\title{
Evaluation of Remotely Sensed Precipitation and Its Performance for Streamflow Simulations in Basins of the Southeast Tibetan Plateau
}

\author{
Sheng Wang, ${ }^{*,+}$ Suxia LiU, ${ }^{*+}{ }^{+}$Xingguo Mo, ${ }^{*}$ Bin Peng, ${ }^{\#}$ JianXiu QiU, ${ }^{*}$ \\ MingXIN Li, ${ }^{@}$ CHANGMING LiU,* ZhONGGEN WANG,* AND \\ PETER BAUER-GOTTWEIN ${ }^{\&,+}$ \\ * Key Laboratory of Water Cycle and Related Land Surface Processes, Institute of Geographic Sciences \\ and Natural Resources Research, Chinese Academy of Sciences, Beijing, China \\ ${ }^{+}$Sino-Danish Center for Education and Research and Sino-Danish College of University of \\ Chinese Academy of Sciences, Beijing, China \\ \# State Key Laboratory of Remote Sensing Science, Institute of Remote Sensing and Digital Earth, \\ Chinese Academy of Sciences, Beijing, China \\ ${ }^{\circledR}$ Bureau of Hydrology, Changjiang Water Resources Commission, Wuhan, China \\ ${ }^{\&}$ Department of Environmental Engineering, Technical University of Denmark, Kongens Lyngby, Denmark
}

(Manuscript received 2 September 2014, in final form 13 July 2015)

\begin{abstract}
Four satellite-based precipitation products [TMPA real time (T-rt), its gauge-adjusted version (T-adj), Climate Prediction Center (CPC) morphing technique (CMORPH) real time (C-rt), and its gauge-adjusted version $(\mathrm{C}$-adj)] were evaluated by a gauge-based synthesis dataset. Further, these products along with the CMORPH gauge-satellite blended version (C-ga), which is virtually $\mathrm{C}$-adj in precipitation ungauged regions and is controlled by gauge analysis over regions of a dense station network, were intercompared with daily streamflow predicted by the distributed vegetation interface processes (VIP) model in the Lhasa and Gongbo basins of the southeast Tibetan Plateau. Results show these satellite-based products perform better in summer than in other seasons. Relative to the gauge-based synthesis dataset, for areal precipitation of the Lhasa basin from 2007 to 2010, biases of C-rt and T-rt are $-10.49 \%$ and $157.88 \%$, respectively. Biases of C-adj and T-adj are $3.42 \%$ and $24.12 \%$, respectively. The C-rt bias is underestimation of the volume of observed rainfall correctly detected and overestimation of the volume of falsely alarmed rainfall, while T-rt bias comes from overestimation of the volume of observed rainfall correctly detected. Simulation efficiencies of stream discharges driven by $\mathrm{T}$-adj and $\mathrm{C}$-adj are better than those by $\mathrm{T}$-rt and C-rt, which are consistent with the accuracies of these products. With benchmarked model parameters using the gauge-based dataset, C-adj presents well for simulation, while $\mathrm{T}$-adj needs parameter recalibration to achieve good skills. Compared to $\mathrm{T}$-adj and $\mathrm{C}$-adj, better simulation could be obtained by $\mathrm{C}$-ga in precipitation-gauged regions.
\end{abstract}

\section{Introduction}

Precipitation inputs are essential for hydrological simulation, whereas in the data-sparse regions, the availability of accurate precipitation is restricted by sparse gauges. As alternatives, satellite-based precipitation products, with the massive growth during the last decade, could provide high temporal and spatial resolution quasiglobal precipitation estimates (Kidd and Levizzani 2011).

Corresponding author address: Suxia Liu, Key Laboratory of Water Cycle and Related Land Surface Processes, Institute of Geographic Sciences and Natural Resources Research, Chinese Academy of Sciences, 11A Datun Road, Chaoyang District, Beijing 100101, China. E-mail: liusx@igsnrr.ac.cn
This significantly facilitates hydrological predictions in data-scarce regions (Stisen and Sandholt 2010; Hrachowitz et al. 2013). The Tibetan Plateau is the highest plateau in the world and the source of several large rivers. Hydrological simulation in the Tibetan Plateau is motivated by the improved understanding of hydrological dynamics and water resource management issues (Bookhagen and Burbank 2010; Immerzeel et al. 2010; Michailovsky et al. 2013; Zhang et al. 2013; Lutz et al. 2014). However, the estimation of precipitation in this region is challenging, and different precipitation datasets present quite diverse results (Palazzi et al. 2013; Tong et al. 2014a).

There are numerous quasi-global satellite-based precipitation products, such as the Tropical Rainfall Measuring Mission (TRMM) Multisatellite Precipitation 
Analysis (TMPA; Huffman et al. 2007), the Climate Prediction Center morphing technique (CMORPH; Joyce et al. 2004), and the Precipitation Estimation from Remotely Sensed Information Using Artificial Neural Networks (PERSIANN) method (Sorooshian et al. 2000). The evaluation of satellite-based precipitation products is necessary as to provide feedbacks for the retrieval algorithm improvement (Yong et al. 2015) and give implications to select the precipitation dataset for local hydrological applications (Thiemig et al. 2013). The evaluation could be conducted by using statistical and hydrological simulation approaches (Yilmaz et al. 2005; Bitew and Gebremichael 2011; Bitew et al. 2012; Peng et al. 2014). Direct statistical validation is performed between the estimates of satellite-based precipitation products in the grid to point or grid to grid with in situ observations. But this involves uncertainties related to the scaling, especially in the region with complex land forms. As runoff integrates the hydrological dynamics over the basins, the hydrological simulation approach could use the observed discharge to validate the simulated discharge and then to evaluate the hydrological model's precipitation inputs. Such an approach is not subject to the scale discrepancy and could serve as a complement to the statistical validation. Furthermore, as a specific application, the hydrological simulation approach could provide information on the reliability of precipitation datasets for hydrological utilities (Bitew and Gebremichael 2011).

Several studies have been conducted to evaluate satellite-based precipitation products over the Tibetan Plateau (Yin et al. 2008; Gao and Liu 2013; Meng et al. 2014; Tong et al. 2014b). These studies revealed that among the TMPA real-time version (T-rt hereafter), TMPA gauge-adjusted version ( $\mathrm{T}$-adj hereafter), CMORPH real-time version (C-rt hereafter), and PERSIANN, $\mathrm{T}$-adj and C-rt, which blended the microwave and infrared radiation information, performed relatively well for precipitation estimates in the Tibetan Plateau. But these studies focused on either solely statistical evaluation or hydrological simulation over large-scale basins, for example, the upper reaches of Yellow River and Yangtze River. The performance of hydrological simulation forced by satellite-based precipitation products strongly associates with basin scales and the application for streamflow simulation in the small basins suffers poorer performances than that in large basins (Nikolopoulos et al. 2010; Vergara et al. 2014). The suitability of these satellite-based precipitation products for hydrological simulation in mesoscale basins and in the southeast Tibetan Plateau has not been explored and needs to be identified. Furthermore, several new satellite-based precipitation products, such as CMORPH gauge-adjusted product (C-adj hereafter) and the CMORPH gauge-satellite blended precipitation product (C-ga hereafter), have reported improved performance for precipitation estimates (Xie et al. 2011, 2013). Thus, the purpose of this study is designed to evaluate the five satellite-based precipitation products (T-rt, T-adj, C-rt, C-adj, and C-ga) through statistical validation against a gauge-based synthesis dataset and hydrological simulation approaches in two mesoscale basins (Lhasa and Gongbo) over the southeast Tibetan Plateau.

\section{Study area, data, and methods}

\section{a. Satellite precipitation products}

Five state-of-the-art high-resolution precipitation products from TMPA series and CMORPH series, T-rt, T-adj, C-rt, C-adj, and C-ga, were examined here. All these products have a $0.25^{\circ} \times 0.25^{\circ}$ spatial resolution and a 3-h temporal resolution except C-ga, which has a daily temporal resolution. T-rt and C-rt are the raw realtime satellite-based products, which integrated infrared (IR) and passive microwave (PMW) observations, and have a short latency about 3-9 and $18 \mathrm{~h}$, respectively. T-adj, C-adj, and C-ga are the research products, which have been calibrated or merged with gauge observations. (The TMPA series were downloaded from http:// mirador.gsfc.nasa.gov/. The CMORPH series were downloaded from ftp.cpc.ncep.noaa.gov.) Except for T-rt, which is not available before March 2000, all the products are available from 1998. For detailed descriptions, refer to Huffman et al. (2007), Joyce et al. (2004), and Xie and Xiong (2011). Here, a brief summary for the algorithms of these precipitation datasets is provided for content integrity.

Observations from a list of PMW sensors are merged into the TMPA series, including the TRMM Microwave Imager (TMI) on TRMM; the Special Sensor Microwave Imager (SSM/I) on the early launched Defense Meteorological Satellite Program (DMSP) satellite series (DMSP-F13-F15) and later Special Sensor Microwave Imager/Sounder (SSMIS) on DMSP-F16-F18; Advanced Microwave Scanning Radiometer for Earth Observing System (AMSR-E) on Aqua; the Advanced Microwave Sounding Unit B (AMSU-B) on the National Oceanic and Atmospheric Administration (NOAA) satellite series (NOAA-15-17) and the Microwave Humidity Sounder (MHS) on a later NOAA satellite (NOAA-18); and the European Meteorological Operation (MetOp) satellites. The processing algorithms of the TMPA series could be summarized as the following sequential steps: 1) calibration and combination of microwave precipitation estimates, 2) using the calibrated microwave precipitation 
to estimate IR precipitation, and 3) merging of microwave and IR estimates (Huffman et al. 2007). Besides these steps for T-rt, T-adj is further produced by calibrating the merged products T-rt against the TRMM $2 \mathrm{~B} 31$ product, which integrates TRMM Precipitation Radar rainfall estimates, and the monthly gauge analysis from Global Precipitation Climatology Centre (GPCC) and Climate Anomaly Monitoring System (CAMS). Compared with the earlier version of the TMPA series, the latest version 7 of the TMPA series has more PMW datasets (early data records from MHS and the entire operational SSMIS data records) as well as new IR datasets (GridSat-B1) enrolled. In addition, version 7 of the TMPA series also features uniform reprocessing of input data, a single surface precipitation gauge analysis, as well as a latitude calibration scheme (Huffman et al. 2010).

Different from the products of the TMPA series, the CMORPH series use precipitation estimates that have been derived from PWM observations exclusively. IR observations are only used to produce spatial propagation vector matrices of the precipitation (Joyce et al. 2010). Thus, the precipitation estimates of C-rt heavily depend on the PMW observations. The precipitation estimates of C-rt incorporate the algorithms of Ferraro (1997) for SSM/I, Ferraro et al. (2000) for AMSU-B, and Kummerow et al. (2001) for TMI. Besides these steps for C-rt, the gauge-adjusted product C-adj (Xie et al. 2011) utilizes the information from ground measurements by precipitation probability distribution function (PDF) matching against daily gauge data to remove the bias over a spatial domain of $5^{\circ}$, centering at the target grid box and over a time period of 30 days. Another dataset from the CMORPH series is C-ga, which is a gauge-CMORPH blended daily precipitation dataset. This dataset combined $\mathrm{C}$-adj and gauge analysis through the optimal interpolation (OI) assimilation method, in which $\mathrm{C}$-adj is used as the first guess while the gauge analysis is used as observations to refine the first guess (Xie and Xiong 2011).

All the 3-hourly coordinated universal time (UTC) datasets (T-rt, T-adj, C-rt, and C-adj) have been transformed and accumulated to local standard time (LST) daily products.

\section{b. Study area and hydrometeorological data}

\section{1) BASIN DESCRIPTION}

The Lhasa and Nyang Rivers are two tributaries of the Yarlung Zangbo (Upper Brahmaputra) River in the southeast Tibetan Plateau, as shown in Fig. 1a. The basin draining to the Lhasa hydrological station (namely, the Lhasa basin) has an area of $26235 \mathrm{~km}^{2}$ and the basin over the Gongbo hydrological station (namely, the Gongbo basin) is $6417 \mathrm{~km}^{2}$. Mean annual discharges are $361 \mathrm{~m}^{3} \mathrm{~s}^{-1}$ at Lhasa and $128 \mathrm{~m}^{3} \mathrm{~s}^{-1}$ at Gongbo, respectively. The most part of this region has an elevation range from 4700 to $5300 \mathrm{~m}$ MSL. (Fig. 1b). This area is a typical monsoondominated alpine region with distinct wet (from May to October) and dry seasons (from November to next April). The precipitation during the wet seasons, especially from June to September, accounts for most of the total yearly precipitation, and the weather is characterized by intense solar radiation, low air temperature, and strong daily variations of air temperature ( $\mathrm{Li}$ et al. 2014). In these two basins, grassland, shrub, and barren land are the principal land-cover types (Fig. 1c). Soil texture is dominated by sandy loam and loam (Fig. 1d). This region has a small population and limited human activities; thus, these two rivers can be considered pristine rivers.

\section{2) Hydrometeorological dAtA}

The ground observations of meteorological and hydrological variables in this region were collected from 14 Chinese Meteorological Administration (CMA) meteorological stations and 6 Hydrology and Water Resource Survey (HWRS) hydrological stations, as shown in Fig. 1a. The CMA dataset includes the daily precipitation; maximum, minimum, and mean air temperature; air water vapor pressure; wind speed; and sunshine duration (http:// www.cma.gov.cn/2011qxfw/2011qsigx/). The HWRS hydrological datasets including the observed discharge, precipitation, and mean air temperature were obtained from HWRS, the Tibet Autonomous Region of China, and only parts of this dataset are available for this study. The observed daily discharge of the Lhasa hydrological station is available from 2000 to 2008 and that of the Gongbo hydrological station is from 2000 to 2010 . The monthly precipitation records for the Tangya and Pondo hydrological stations are available from 2001 to 2003 and those for Gongbo and Gengzhang stations are available from 1998 to 2007. The daily mean air temperature records are available from January 2000 to December 2003 in Pondo, Tangya, and Lhasa stations and from January 2000 to May 2003 in Gongbo, Gengzhang, and Bayi stations.

As the model inputs, the meteorological variables such as air water vapor pressure, wind speed, and sunshine duration were interpolated to the gridded datasets by the inverse distance square (IDS) algorithm with topographic correction (Mo et al. 2004). The precipitation and temperature lapse rates have great impacts on the water balance composition in alpine basins (Immerzeel et al. 2014); thus, the gridded datasets for precipitation and temperature were carefully selected and constructed.

The precipitation lapse rates in the alpine basins are usually very complex, and a uniform valleywide precipitation lapse rate is hard established (Immerzeel et al. 
(a)

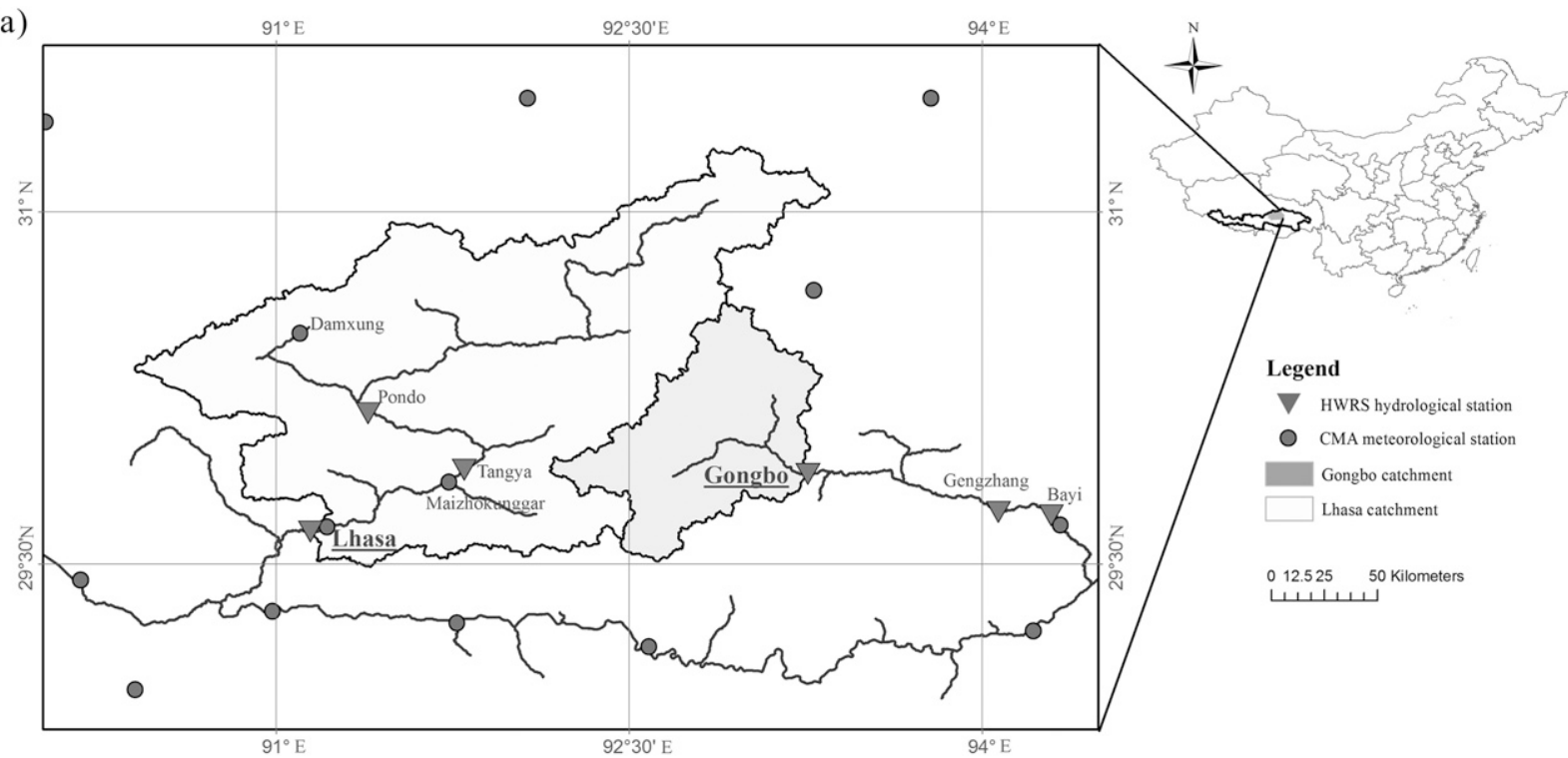

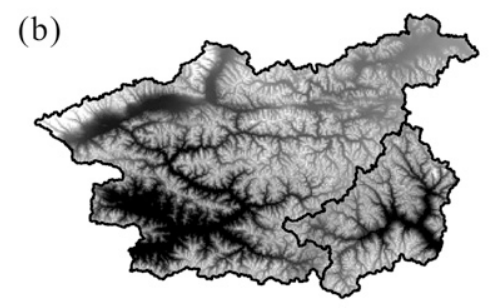

Elevation (m)

High : 8000 (c)

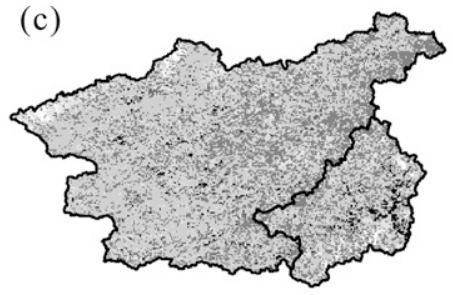

Land use

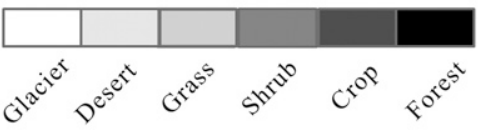

(d)

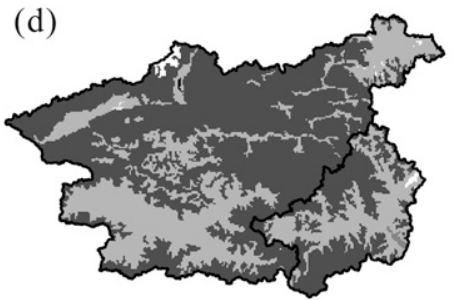

Soil texture

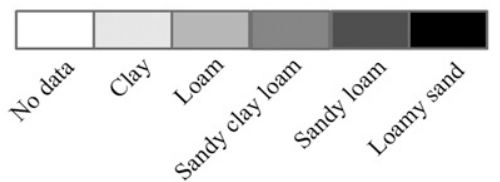

FIG. 1. Map and basic information of the study area. (a) Location of the Lhasa and Gongbo basins, hydrological stations, and meteorological stations. (b) Elevation. (c) Land use. (d) Soil texture.

2014). Different lapse rates have been reported in this region (e.g., Ohta et al. 1994; Xie et al. 2009; Lin et al. 2001; Lu et al. 2007). Therefore, instead of constructing a gridded precipitation dataset by IDS with a single lapse rate, a gridded precipitation dataset with a complex interpolation algorithm was employed for statistical validation and model inputs. This gridded gauge-based precipitation dataset (called IGSNRR hereafter) was established by Zhang et al. (2014) from the Institute of Geographic Sciences and Natural Resources Research. This dataset covers the whole of China with a $0.25^{\circ}$ grid and was interpolated based on the daily precipitation observations of 756 CMA stations, in which 14 meteorological stations in this region were included. This dataset used the synergraphic mapping system (SYMAP) algorithm of Shepard (1984) by adjusting the 12 monthly means with 12 scaling factors in each grid cell to match the monthly means of the CMA precipitation product in 1962-2002 (Maurer et al. 2002; Tang et al. 2009). The CMA precipitation product covers East Asia with a spatial resolution of $0.5^{\circ}$ and was produced using more than 756 precipitation gauges in China (Xie et al. 2007). Detailed information can be referred to Zhang et al. (2014). To examine the performance of IGSNRR in this region, the independent monthly precipitation records from four available HWRS hydrological stations (Tangya, Pondo, Gongbo, and Gengzhang) were used. As shown in Fig. 2, the high correlation coefficients and the slopes close to 1 demonstrate that IGSNRR gets a good estimation of precipitation in this region. These independent precipitation data were also used to examine Asian Precipitation-Highly Resolved Observational Data Integration Towards Evaluation of Water Resources (APHRODITE) (Yatagai et al. 2012), which is a commonly used gauge-based precipitation dataset in the Himalaya region (Lutz et al. 2014). The results show that 
(a)

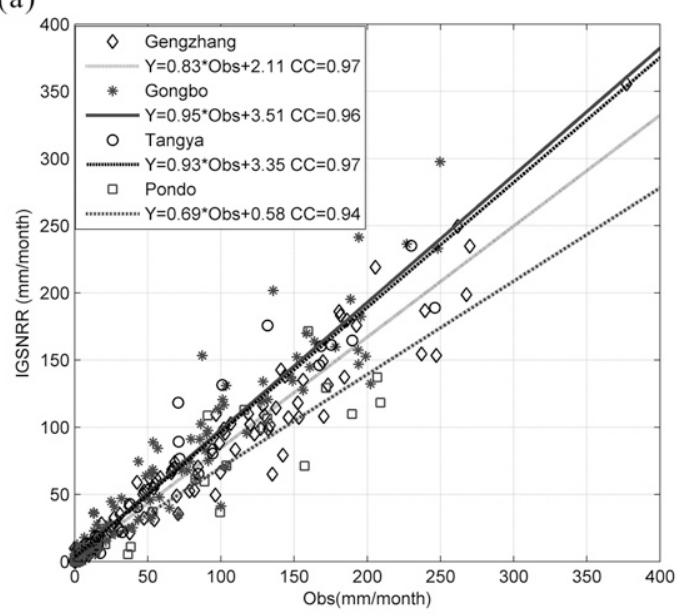

(b)

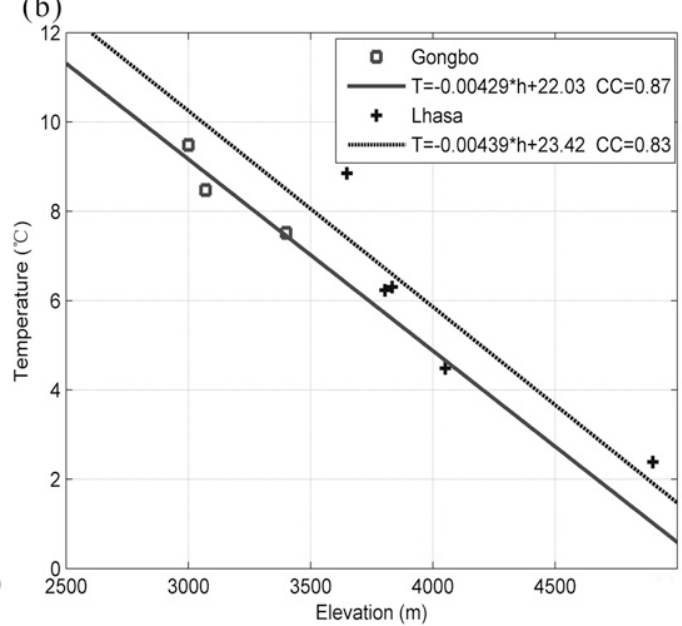

FIG. 2. (a) The IGSNRR precipitation dataset vs the independent monthly precipitation observations from four HWRS hydrological stations (Gengzhang, Gongbo, Tangya, and Pondo). (b) The vertical temperature lapse rates with elevation below $4965 \mathrm{~m}$ in the Gongbo and Lhasa basins.

the performance of IGSNRR is slightly better than APHRODITE. Generally, IGSNRR could serve as the reference precipitation dataset for this region.

The vertical air temperature lapse rates are important climatic variables in determining the glacier and snowmelt in alpine basins (Lutz et al. 2014). According to the in situ observations from 11 automated weather stations set up along an altitudinal transect on the southern slope of west Nyainqentanglha Mountains from August 2006 to October 2008, the mean monthly lapse rate ranged from $0.68^{\circ}$ to $0.88^{\circ} \mathrm{C}(100 \mathrm{~m})^{-1}$ for the place with elevation above $4965 \mathrm{~m}$, while the lapse rates for the place lower than the critical elevation of $4965 \mathrm{~m}$ were less than $0.5^{\circ} \mathrm{C}(100 \mathrm{~m})^{-1}$ (Xie 2010). The relationship between elevation and all available observed daily mean temperature records from these CMA and HWRS stations in these basins was analyzed as Fig. 2b. The estimated temperature lapse rates $0.44^{\circ} \mathrm{C}(100 \mathrm{~m})^{-1}$ for the Lhasa basin and $0.43^{\circ} \mathrm{C}(100 \mathrm{~m})^{-1}$ for the Gongbo basin were used for the region below $4965 \mathrm{~m}$. The temperature lapse rate above this critical elevation was estimated by the hydrological model parameter calibration.

\section{c. The statistical validation approach}

In the statistical validation, the numbers of grids with missing values in these satellite gridded precipitation datasets at the Lhasa and Gongbo basins were examined. The examination focused on the period in which these grids occurred and the proportion of these grids compared to the whole basins. Symeonakis et al. (2009) found the grid-to-grid method yielded more robust results than the grid-to-point validation method. Here, the grid-to-grid method was adopted and IGSNRR was employed to validate these satellite-based precipitation datasets. A set of statistical indices were adopted, including three commonly used contingency table indices (Wilks 2006), to assess the ability of satellite data to detect the occurrence of precipitation: probability of detection (POD), false alarm ratio (FAR), critical success index (CSI), and two extended volumetric indices (AghaKouchak and Mehran 2013) [volumetric false alarm ratio (VFAR) and volumetric critical success index (VCSI)] and three traditional volumetric indices, including absolute bias (AB), relative bias (bias), and the correlation coefficient (CC). These indices are calculated by Eqs. (1)-(8), respectively. A higher score of POD, CSI, and VCSI and a lower score of FAR, VFAR, and AB represent better skills of precipitation products:

$$
\begin{aligned}
\mathrm{POD} & =\frac{H}{H+M}, \\
\mathrm{FAR} & =\frac{F}{H+F}, \\
\mathrm{CSI} & =\frac{H}{H+M+F}, \\
\mathrm{VFAR} & =\frac{\mathrm{VF}}{\mathrm{VH}+\mathrm{VF}}, \\
\mathrm{VCSI} & =\frac{\mathrm{VH}}{\mathrm{VH}+\mathrm{VM}+\mathrm{VF}}, \\
\mathrm{AB} & =\frac{\sum_{i=1}^{N}\left|S_{i}-G_{i}\right|}{\sum_{i=1}^{N} G_{i}},
\end{aligned}
$$




$$
\begin{aligned}
& \operatorname{bias}=\frac{\sum_{i=1}^{N}\left|S_{i}-G_{i}\right|}{\sum_{i=1}^{N} G_{i}}, \text { and } \\
& \mathrm{CC}=\frac{\sum_{i=1}^{N}\left(G_{i}-\bar{G}\right)\left(S_{i}-\bar{S}\right)}{\sqrt{\sum_{i=1}^{N}\left(G_{i}-\bar{G}\right)^{2}} \times \sqrt{\sum_{i=1}^{N}\left(S_{i}-\bar{S}\right)^{2}}},
\end{aligned}
$$

where $H$ is the number of observed rain correctly detected; $M$ is the number of observed rain but not detected; and $F$ is the number of rainfall detected but not observed. The $\mathrm{VH}$ is the volume of satellite estimates in the situation where observed rain is correctly detected. The VF is the volume of satellite estimates in the situation where rainfall is detected but not observed. The VM is the volume of observed estimates in the situation where observed rainfall is not detected. For detailed information about volumetric-based metrics, refer to AghaKouchak and Mehran (2013). The terms $S_{i}$ and $G_{i}$ are the satellite estimates and gauge observations, respectively. The quantity $i$ is the time (day, $i=1, \ldots, N)$, and $N$ is the total number.

Besides the grid-to-grid validation, the daily precipitation amount of these datasets was compared at each quantile in the Lhasa and Gongbo basins by the quantilequantile $(\mathrm{Q}-\mathrm{Q})$ plot. The $\mathrm{Q}-\mathrm{Q}$ plot is a graphical method used to compare two probability distributions by plotting their quantiles against each other. To explore these satellite-based precipitation products' performance in different seasons, the values of areal precipitation for the Lhasa basin from these satellite-based products were also compared against IGSNRR.

\section{d. The hydrological simulation approach}

The process-based ecohydrological model vegetation interface processes (VIP) model (Mo et al. 2004) was employed to simulate the streamflow in Lhasa and Gongbo basins with $1-\mathrm{km}^{2}$ spatial resolution.

\section{1) VIP MODEL STRUCTURE}

The VIP model can simulate the rainfall interception, snow dynamics, melting of glaciers, transpiration, evaporation, infiltration, percolation, capillary rise, groundwater flow, overland runoff, streamflow, photosynthesis, and other detailed ecohydrological processes. The main modules used in this study include 1) a multilayer canopy radioactive transfer module; 2 ) a two-source soil-canopy energy balance module; 3) a multiple-layer soil water and energy transfer module; 4) a modified variable infiltration capacity scheme for runoff generation; 5) the degree-day factor method for snow and ice melt computation; and 6) the kinematic wave scheme for streamflow routing. The VIP model has been applied and validated extensively in basins across China (Mo and Liu 2001; Mo et al. 2004, 2014; Liu et al. 2009; Huang and Mo 2015). Details about the model can be referred to Mo and Liu (2001) and Mo et al. (2004). Here, the scheme for runoff generation and routing was briefly introduced.

This model operated the runoff generation in each grid as follows. 1) The interception of rainfall was calculated as a ratio of rainfall intensity and leaf area index (LAI). 2) The net precipitation was partitioned to surface runoff and infiltration using a modification of the variable infiltration capacity scheme (Mo et al. 2004), which originated from the Xinanjiang model (Zhao 1992). 3) The transpiration is coupled with photosynthesis, calculated separately on shaded and sunlit leaves. Canopy and underneath soil surface energy balance equations are solved simultaneously for latent (evaporation and transpiration) and sensible heat fluxes. 4) Glacier melt, snow accumulation, and melt processes were implemented using a temperature index method. 5) The soil water movement was simulated with the discrete Richards equation in a six-layer scheme, in which soil evaporation originated from the first layer and plant roots took up water from the second to fifth layer. 6) The groundwater recharge from the sixth soil layer was calculated by Darcy's Law. 7) The upper and lower linear reservoirs were employed to simulate the drainage of groundwater to channels. 8) The overland and channel runoff routing was computed based on the kinematic wave equation solved by a one-dimensional four-point finite backward-difference method.

\section{2) VIP MODEL IMPLEMENTATION}

The interpolated, gridded, daily maximum, minimum, and mean air temperature, air water vapor pressure, wind speed, and sunshine duration from observations of 14 CMA stations, spanning from 1998 to 2010, were used for the model inputs. The 3-arc-s SRTM elevation data were downloaded from United States Geological Survey (USGS; http://gdex.cr.usgs.gov/gdex/), as shown in Fig. 1b. Based on this data, the slope, flow direction, and river channel network were calculated. The 8-day LAI data from 2000 to 2010 were obtained from Moderate Resolution Imaging Spectroradiometer (MODIS; http:// modis.gsfc.nasa.gov). The MODIS land-cover data in 2001 were downloaded and adjusted to match the categories of VIP land-cover inputs (Fig. 1c). The glacier distribution information was obtained from the second glacier inventory dataset of China (Guo et al. 2014). The soil texture (Fig. 1d) and depth information was obtained from FAO Harmonized World Soil Database v1.2 (FAO et al. 2012). The observed daily discharges in the Lhasa and Gongbo hydrological stations were 
TABLE 1. Overview of the key parameters for streamflow simulation.

\begin{tabular}{|c|c|c|c|c|c|c|}
\hline Parameter & Description & Unit & Range & Lhasa & Gongbo & Source \\
\hline Cs & Snow degree-day factor & $\mathrm{mm}^{\circ} \mathrm{C}^{-1}$ day $^{-1}$ & - & 4.1 & 4.1 & Zhang et al. (2006) \\
\hline $\mathrm{Ci}$ & Ice degree-day factor & $\mathrm{mm}{ }^{\circ} \mathrm{C}^{-1}$ day $^{-1}$ & - & 9.0 & 9.0 & Zhang et al. (2006) \\
\hline$\lambda 1$ & $\begin{array}{l}\text { Temperature lapse rate above the } \\
\text { critical elevation }\end{array}$ & ${ }^{\circ} \mathrm{C}(100 \mathrm{~m})^{-1}$ & $\begin{aligned} \sim(0.68-0.88) \\
\quad(\text { Xie 2010) }\end{aligned}$ & 0.68 & 0.68 & Calibrated \\
\hline$H$ & $\begin{array}{l}\text { Critical elevation for the temperature } \\
\text { lapse rate }\end{array}$ & $\mathrm{m}$ & - & 4965 & 4965 & Xie (2010) \\
\hline$\lambda 2$ & $\begin{array}{l}\text { Temperature lapse rate below the } \\
\text { critical elevation }\end{array}$ & ${ }^{\circ} \mathrm{C}(100 \mathrm{~m})^{-1}$ & $\begin{array}{l}<0.5 \\
(\text { Xie 2010) }\end{array}$ & 0.44 & 0.43 & Observed \\
\hline$B$ & $\begin{array}{l}\text { Shape parameter of the variable } \\
\text { infiltration curve }\end{array}$ & $\mathrm{mm}$ & $\sim(0.1-10)$ & 4.8 & 5.1 & Calibrated \\
\hline$N$ & $\begin{array}{l}\text { Channel Manning roughness } \\
\text { coefficients }\end{array}$ & & $\sim(0.001-1)$ & 0.05 & 0.05 & Calibrated \\
\hline Tguz & $\begin{array}{l}\text { Upper zone transmissivity of } \\
\text { groundwater }\end{array}$ & $\mathrm{mm} \mathrm{s}^{-1}$ & $\sim(0.0005-0.4)$ & 0.07 & 0.0002 & Calibrated \\
\hline Tglz & $\begin{array}{l}\text { Lower zone transmissivity of } \\
\text { groundwater }\end{array}$ & $\mathrm{mm} \mathrm{s}^{-1}$ & $\sim(0.00001-0.1)$ & 0.007 & 0.0001 & Calibrated \\
\hline
\end{tabular}

used for the hydrological model calibration and validation in these two basins, separately.

The VIP model was run to simulate the streamflow from 1998 to 2008 in the Lhasa basin and from 1998 to 2010 in the Gongbo basin, with the first 2-yr spinup. The calibration period for the streamflow simulation in the Lhasa basin is from 2000 to 2002, and the validation is from 2003 to 2008. In the Gongbo basin, the calibration period is from 2000 to 2005 , and the validation is from 2006 to 2010. For the model calibration, the global optimization method SCE-UA (Duan et al. 1992; Duan et al. 1993) was utilized to estimate the VIP model parameter values (Table 1) with an objective function as in Eq. (9) to maximize the Nash-Sutcliffe coefficient of efficiency [NSE; Eq. (10)] and minimize streamflow volume error [VE; Eq. (11)]. For the model parameters in the VIP model, some physically based parameters can be derived from land-cover types and soil texture data based on a lookup table. Other key model parameters for streamflow simulations were described in Table 1. The parameter values of the snow and ice degree-day factor were adopted from Zhang et al. (2006). These values have also been used for the simulation of hydrological dynamics in the upper reach of the Yarlung Zangbo River (Zhang et al. 2013). For the rest of parameters that cannot be measured directly, as shown in Table 1, the optimization method was employed to identify these parameter values.

Besides NSE and VE, the Taylor diagrams (Taylor 2001) were used to present three complementary indices, CC, Normalized standard deviation (NSTD), and Normalized unbiased Root Mean Square Error (NubRMSE), to evaluate the simulated discharge, as recently used by Qiu et al. (2013). NSTD and NubRMSE were recalculated from the standard deviation [STD; Eq. (12)] and unbiased RMSE [ubRMSE; Eq. (13)] through normalization by the STD of the observed discharge. These three indices, CC, STD, and ubRMSE, have a triangle cosine law-like relationship, as shown in Eq. (14) (Taylor 2001). In the Taylor diagram, the radial distance stands for the NSTD and the angle in the polar plot represents CC. The reference point located on the $x$ axis with CC $=1$, NSTD $=1$, and NubRMSE $=0$ is the observation. The distance to the reference point means the NubRMSE of simulations and stands for the integrated performance:

$$
\begin{aligned}
F & =1-\mathrm{NSE}+|\mathrm{VE}|, \\
\mathrm{NSE} & =1-\frac{\sum_{i=1}^{N}\left(Q_{o, i}-Q_{s, i}\right)^{2}}{\sum_{i=1}^{N}\left(Q_{o, i}-\overline{Q_{o}}\right)^{2}}, \\
\mathrm{VE} & =\frac{\sum_{i=1}^{N} Q_{s, i}-\sum_{i=1}^{N} Q_{o, i}}{\sum_{i=1}^{N} Q_{o, i}}, \\
\mathrm{STD} & =\sqrt{\sum_{i=1}^{N}(Q-\bar{Q})^{2} / N,} \\
\mathrm{ubRMSE} & =\sqrt{\sum_{i=1}^{N}\left[\left(Q_{s, i}-\overline{Q_{s}}\right)-\left(Q_{o, i}-\overline{Q_{o}}\right)\right]^{2} / N,}
\end{aligned}
$$

and

$$
\begin{aligned}
\mathrm{ubRMSE}_{\mathrm{obs}, \mathrm{sim}}^{2}= & \mathrm{STD}_{\mathrm{obs}}^{2}+\mathrm{STD}_{\mathrm{sim}}^{2} \\
& -2 \mathrm{STD}_{\mathrm{obs}} \mathrm{STD}_{\mathrm{sim}} \cos \mathrm{CC}_{\mathrm{obs}, \mathrm{sim}}
\end{aligned}
$$

where $Q_{o, i}$ is the observed discharge; $Q_{s, i}$ is the simulated discharge; $\overline{Q_{o}}$ is the mean observed discharge; $\overline{Q_{s}}$ is the 
(a) T-rt (May.-Oct.)

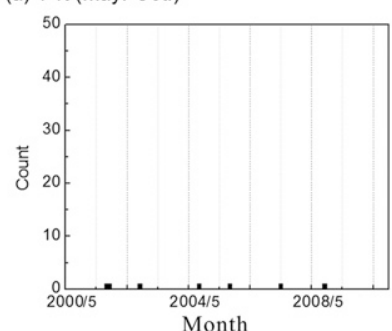

(e) T-rt (Nov.-Apr.)

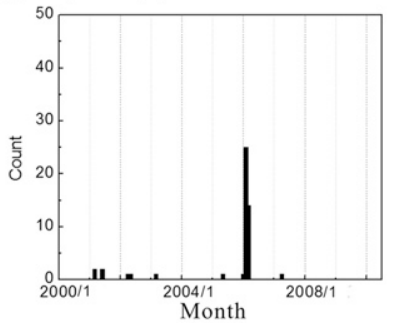

(i) Lhasa T-rt

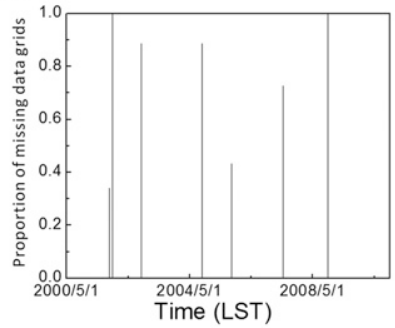

(m) Gongbo T-rt

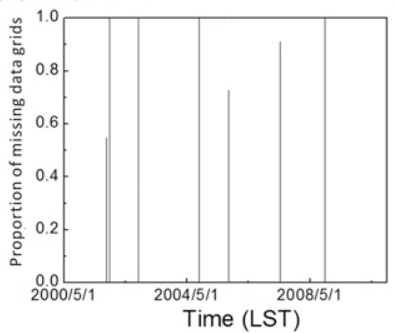

(b) T-adj (May.-Oct.)

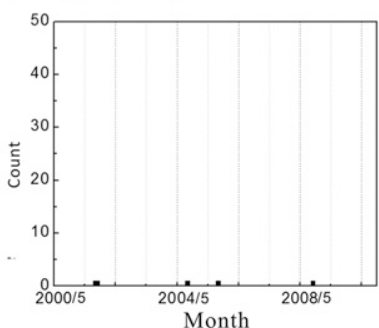

(f) T-adj (Nov.-Apr.)

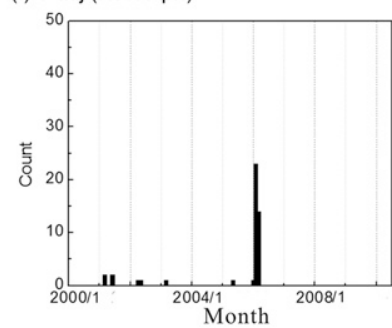

(j) Lhasa T-adj

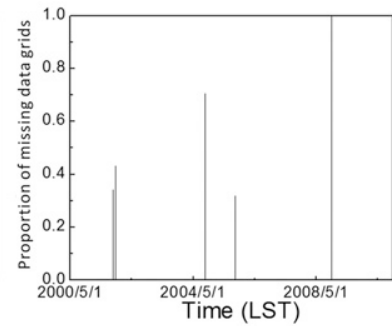

(n) Gongbo T-adj

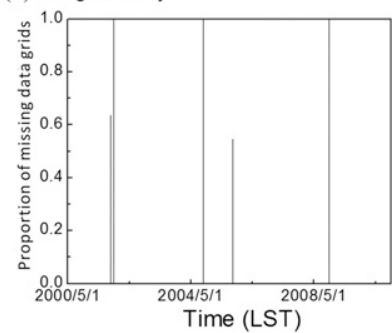

(c) C-rt (May.-Oct.)

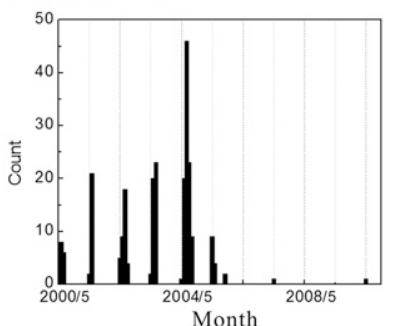

(g) C-rt (Nov.-Apr.)

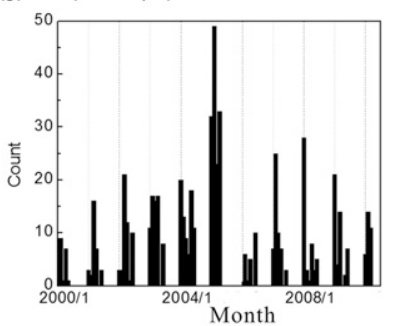

(k) Lhasa C-rt

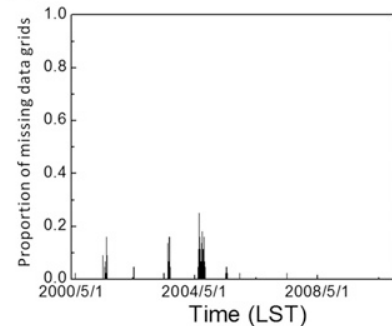

(o) Gongbo C-rt

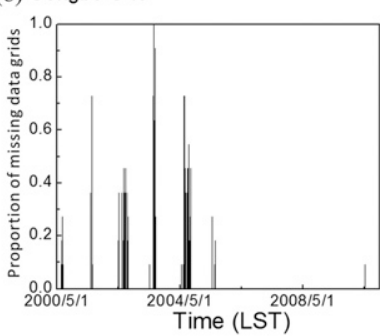

(d) C-adj (May.-Oct.)

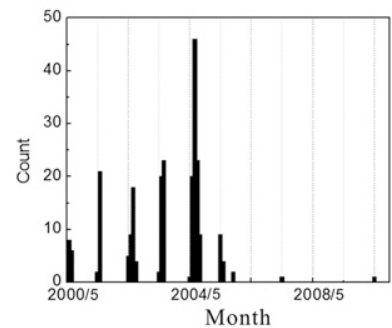

(h) C-adj (Nov.-Apr.)

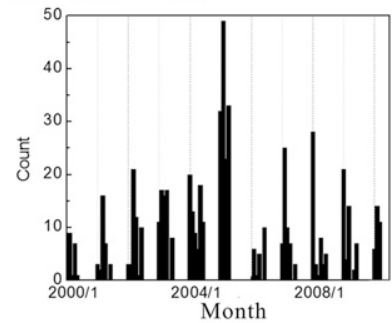

(1) Lhasa C-adj

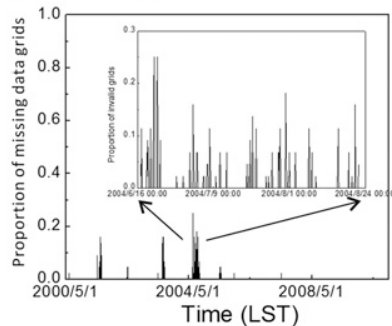

(p) Gongbo C-adj

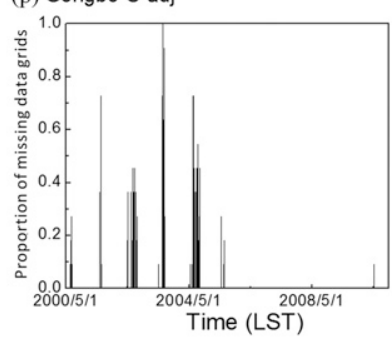

FIG. 3. The statistics of missing grids in the Lhasa and Gongbo basins for (from left to right) T-rt, T-adj, C-rt, and C-adj. (a)-(d) The numbers of missing 3-h intervals in each month from 2000 to 2010 during wet seasons. The total number of 3 -h intervals in one month is 240 $(30 \times 8)$. (e)-(h) As in (a)-(d), but for dry seasons. (i)-(l) The proportions of missing data grids (ratios of missing data grids vs total grids) in each 3-h interval in the Lhasa basin during wet seasons. (m)-(p) As in (i)-(l), but for the Gongbo basin.

mean simulated discharge; $i$ is the time (day, $i=1, \ldots, N)$; and $N$ is the total number.

\section{Results}

\section{a. Statistical validation results}

Before conducting the validation, the missing data in the precipitation products over the Lhasa and Gongbo basins were checked. The information of missing data is shown in Fig. 3. The number of 3-h intervals with missing data (in that $3 \mathrm{~h}$, the dataset contains the missing grids) for each month in T-rt and T-adj (Figs. 3a,b,e,f) is relatively small, while that in C-rt and C-adj (Figs. 3c,d,g,h) is a little high. Most of these missing grids occur during the dry seasons (from November to April) with low precipitation events. Thus, they have limited effects for the daily precipitation accumulation calculation. It should be noticed that the number of missing data for C-rt and $\mathrm{C}$-adj during the wet seasons (from May to October, as shown in Figs. 3c,d) before 2006 is a little high. The ratios of missing grids versus the total grids in the Lhasa and Gongbo basins in these four products 
(a)

IGSNRR

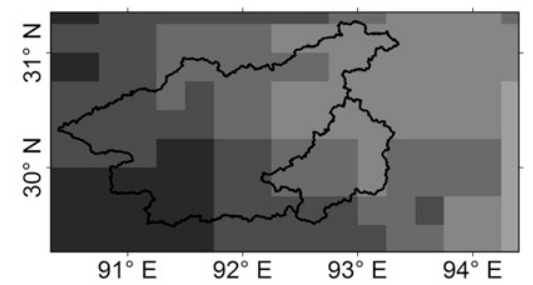

C-rt

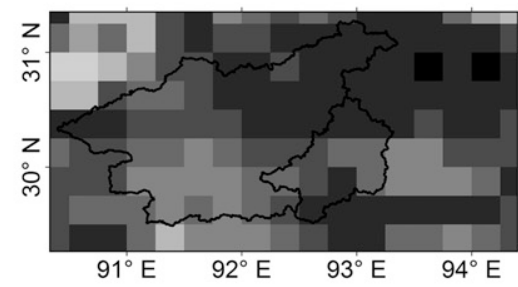

T-rt

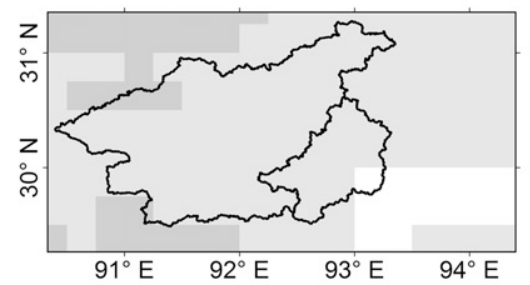

C-adj

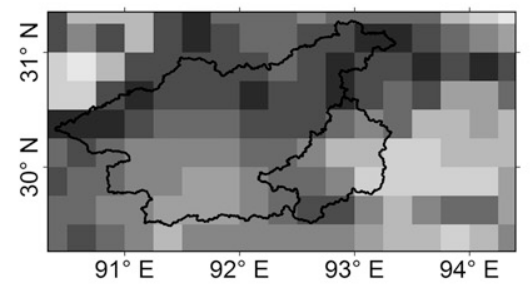

T-adj

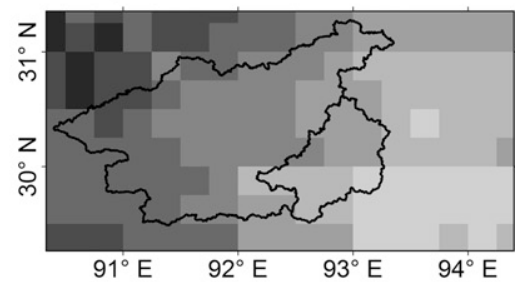

C-ga

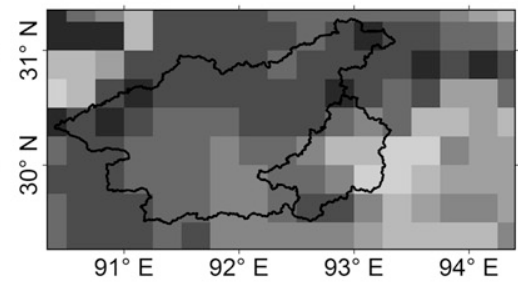

Precipitation ( $\mathrm{mm} /$ year)

(b)

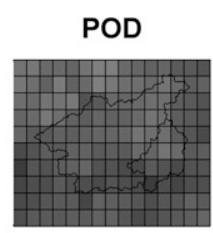

FAR
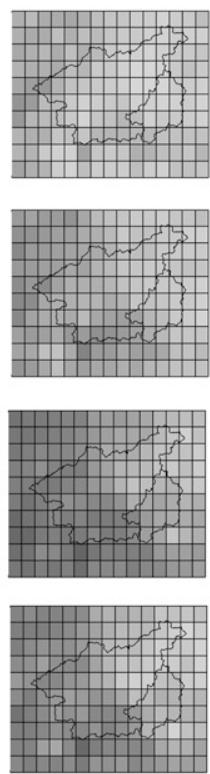

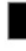

$0 \quad 200 \quad 400 \quad 500 \quad 600 \quad 700 \quad 800 \quad 1,0001,400 \quad 2,400$
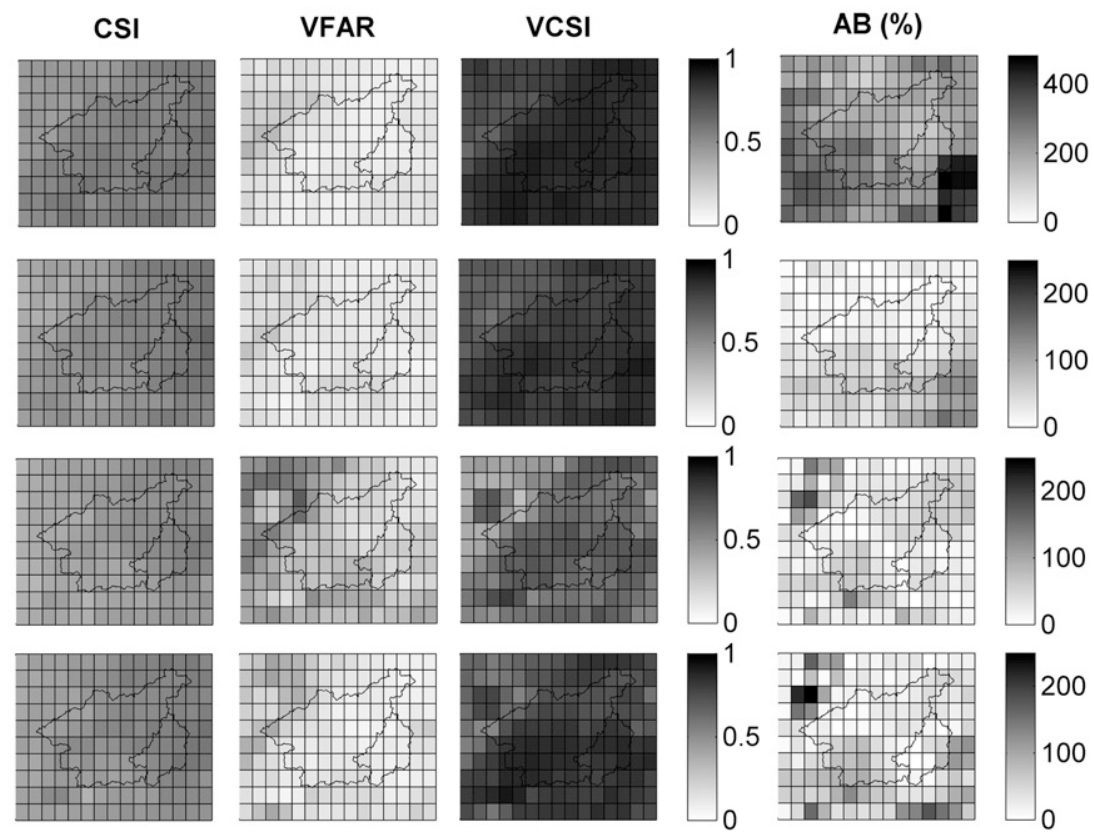

FIG. 4. The grid-to-grid statistical validation of satellite-based precipitation products from 2007 to 2010. (a) The multiyear average of annual precipitation from 2007 to 2010 for IGSNRR, T-rt, T-adj, C-rt, C-adj, and C-ga. (b) POD, FAR, CSI, VFAR, VCSI, and AB indices for the daily precipitation of (from top to bottom) T-rt, T-adj, C-rt, and C-adj.

during wet seasons are shown in Figs. 3i-p. These ratios in the Lhasa basin are much smaller than these in the Gongbo basins. To reduce the effects of these missing data for the statistical validation, the following strategies are carried out: 1) As most missing data occur in dry seasons, zero was assigned to grids. 2) The statistical validation was conducted from 2007 to 2010 , when the number of missing grids is relatively low.

\section{1) GRID-TO-GRID VALIDATION}

The mean annual precipitation of IGSNRR, T-rt, T-adj, C-rt, C-adj, and C-ga from 2007 to 2010 in this region is shown in Fig. 4a. Generally, as IGSNRR shows, the annual precipitation of this region ranges from 400 to $800 \mathrm{~mm}$, and the precipitation in the eastern part is higher than that in the western part. For the areal 

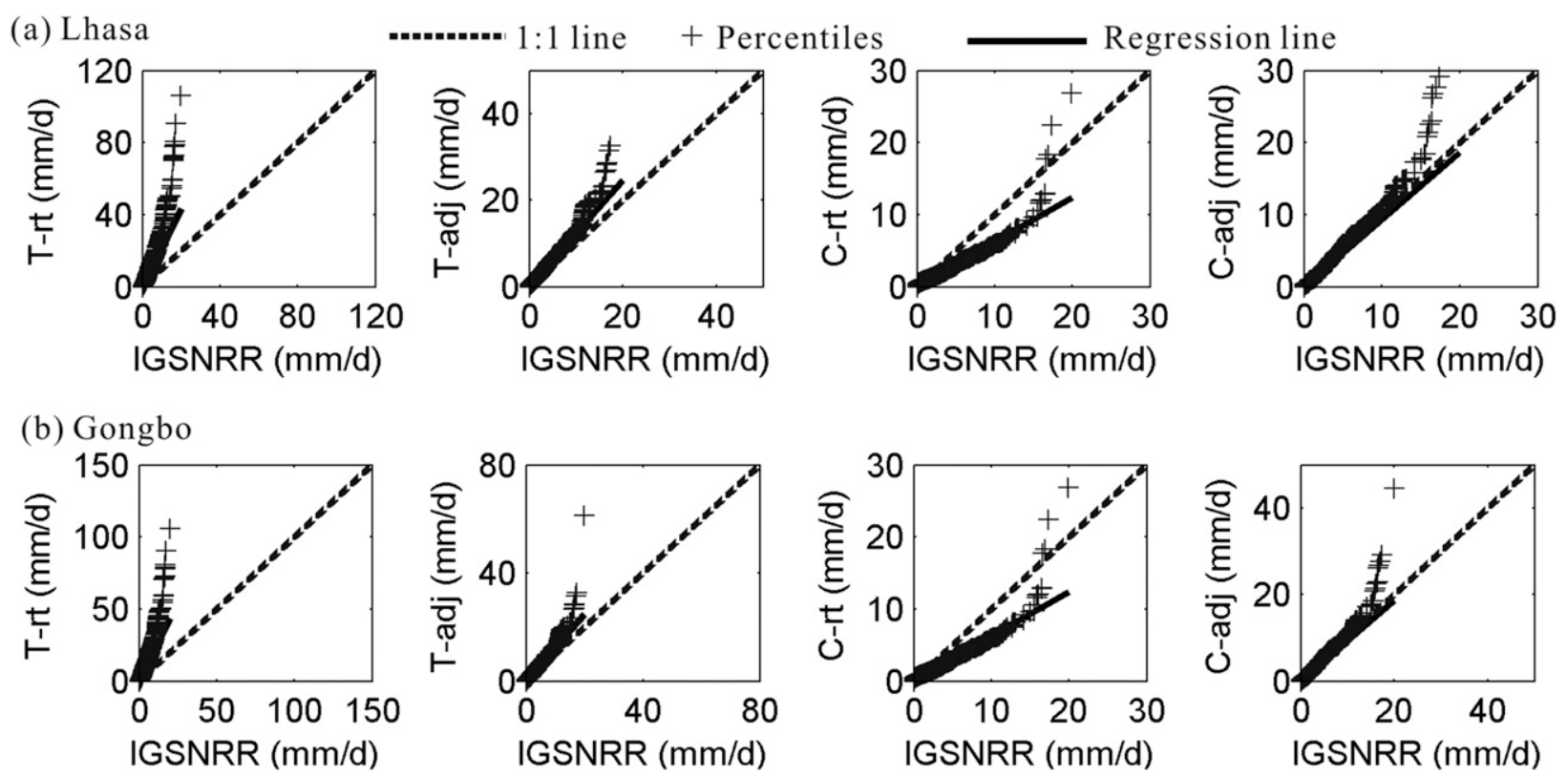

FIG. 5. The Q-Q plots of daily precipitation amount of IGSNRR ( $x$ axis) vs that of the satellite-based precipitation products ( $y$ axis) from 2007 to 2010 for (a) Lhasa and (b) Gongbo. A Q-Q plot is a graphical method for comparing two probability distributions by plotting their quantiles against each other.

precipitation of the Lhasa basin, T-rt obviously overestimates the precipitation with a bias of $157.88 \%$, while C-rt shows underestimation with a bias of $-10.49 \%$. The large overestimation of T-rt precipitation in the Tibetan Plateau has also been reported by Chen et al. (2013) and Yong et al. (2015). Because of the adjustments against gauge-based datasets, initial biases in T-rt and C-rt have been significantly removed in $\mathrm{T}$-adj and $\mathrm{C}$-adj with reduced biases of $24.12 \%$ and $3.42 \%$, respectively. The retrieval algorithms for raw satellite precipitation, calibration procedures, and accuracies of their gauge-based reference datasets attribute to the different performances between $\mathrm{T}$-adj and $\mathrm{C}$-adj.

$\mathrm{C}$-ga merges the gauge-based daily analysis and $\mathrm{C}$-adj. By comparing C-adj and C-ga in the Lhasa and Gongbo basins, as shown in Fig. 4a, the precipitation of C-ga in the Gongbo basin keeps the same as C-adj, while in the Lhasa basin C-ga is different from $\mathrm{C}$-adj and becomes similar to IGSNRR. The reason is that the Lhasa basin is gauged and the Gongbo basin is ungauged in terms of precipitation. In the Lhasa basin, C-ga performs similarly to IGSNRR, while in the Gongbo basin, C-ga is close to C-adj. C-ga is mainly controlled by the gauge analysis in the Lhasa basin and is not independent from IGSNRR. Thus, C-ga is excluded in the following statistical validation against IGSNRR.

Three indices were employed to examine the abilities of T-rt, T-adj, C-rt, and C-adj to detect rainfall events as Fig. 4b. A higher POD and CSI and a lower FAR indicate a better performance. T-rt and T-adj have worse POD scores than C-rt and C-adj. However, for FAR scores, T-rt and T-adj tend to be better than C-rt and $\mathrm{C}$-adj. These two metrics show that $\mathrm{C}$-rt and $\mathrm{C}$-adj have a better ability to detect the occurrence of the correct rainfall than T-rt and T-adj, while T-rt and T-adj get fewer falsely alarmed rainfall events than C-rt and C-adj. Generally, from the view of CSI scores, these four datasets have very similar performances for precipitation detection. It should be also noticed that POD, FAR, and CSI are changed from T-rt to T-adj, while these detection indices do not change from $\mathrm{C}$-rt to $\mathrm{C}$-adj. The reason is that $\mathrm{T}$-adj is produced through the calibration of T-rt against the monthly gauge analysis of GPCC, and this direct calibration method will change the initial rainfall detection results in T-rt. C-adj is based on the calibration of $\mathrm{C}$-rt against daily gauge analysis through PDF matching. The PDF matching is a quasiindependent method and is not used to force the $\mathrm{C}$-adj to be the same as the gauge analysis. It does not change the detection performance of precipitation products.

Considering that these three categorical indices cannot provide insights for the volume of the detected rainfall, the volumetric-based indices VFAR (extended from FAR), VCSI (extended from CSI), and AB were also adopted to assess these datasets. For the volume performance, all datasets except C-rt have low proportions of false rainfall volume with VFAR close to 0 and high proportions of rainfall during the observed 

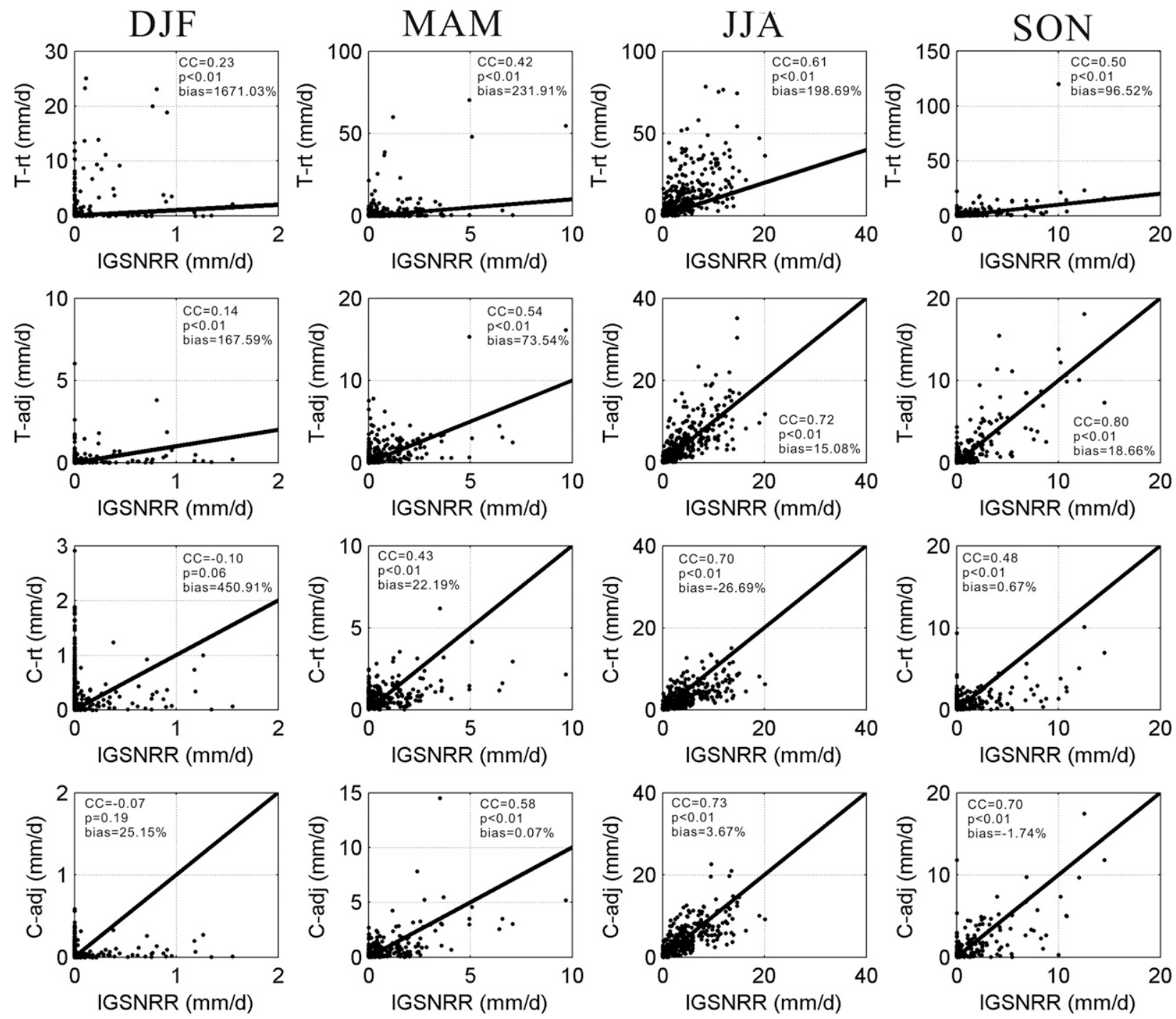

FIG. 6. The scatterplots of daily areal precipitation-IGSNRR vs (from top to bottom) T-rt, T-adj, C-rt, and C-adj-for the Lhasa basin in (from left to right) DJF, MAM, JJA, and SON from 2007 to 2010.

rainfall events with VCSI close to 1 . For AB, T-rt tends to have large volume bias. These two raw satellite estimates, T-rt and C-rt, have larger volume errors than these adjusted datasets. But T-rt volume errors mainly come from overestimation of the amount of observed rainfall correctly detected, while $\mathrm{C}$-rt volume errors are from underestimation of the amount of observed rainfall correctly detected and overestimation of the amount of falsely alarmed rainfall.

\section{2) BASIN-SCALE COMPARISON}

The daily precipitation amount of T-rt, T-adj, C-rt, and $\mathrm{C}$-adj were compared to IGSNRR in the Lhasa and Gongbo basins by the Q-Q plot as shown in Fig. 5. The performances of each product in these two basins are similar. For the real-time versions, T-rt shows much higher daily precipitation amount than IGSNRR, while the amount of C-rt is lower than IGSNRR. However, after adjustment by gauge-based datasets, the daily precipitation amount of $\mathrm{T}$-adj and $\mathrm{C}$-adj fits well with IGSNRR. But for the part of high daily precipitation amount, the estimates from $\mathrm{T}$-adj and $\mathrm{C}$-adj are higher than IGSNRR. In other words, T-adj and C-adj have good agreements with IGSNRR in estimation of the low and medium amount of precipitation, while for the high daily amount precipitation, their estimates are biased.

The performances in four seasons of these satellitebased precipitation products are compared in the Lhasa 
TABLE 2. The comparison of the simulation performances forced by IGSNRR, T-rt, T-adj, C-rt, C-adj, and C-ga in the Lhasa and Gongbo basins.

\begin{tabular}{|c|c|c|c|c|c|c|c|c|}
\hline & & & IGSNRR & T-rt & T-adj & C-rt & C-adj & C-ga \\
\hline \multirow[t]{4}{*}{ Lhasa } & \multirow[t]{2}{*}{ Calibration } & NSE & 0.78 & -17.84 & 0.40 & 0.32 & 0.74 & 0.83 \\
\hline & & VE (\%) & -0.25 & 242.23 & 25.49 & -58.37 & -27.83 & -22.95 \\
\hline & \multirow{2}{*}{ Validation } & NSE & 0.72 & -15.37 & 0.32 & 0.33 & 0.60 & 0.67 \\
\hline & & VE (\%) & 8.83 & 259.84 & 41.13 & -26.75 & -10.11 & -10.75 \\
\hline \multirow[t]{4}{*}{ Gongbo } & \multirow[t]{2}{*}{ Calibration } & NSE & 0.74 & -7.74 & 0.55 & -0.15 & 0.07 & 0.07 \\
\hline & & VE (\%) & -23.40 & 138.66 & -8.52 & -76.17 & -61.57 & -61.34 \\
\hline & \multirow[t]{2}{*}{ Validation } & NSE & 0.73 & -15.63 & -0.42 & 0.30 & 0.42 & 0.38 \\
\hline & & VE (\%) & -5.69 & 199.73 & 18.13 & -39.84 & -8.44 & -8.5 \\
\hline
\end{tabular}

basin, as shown in Fig. 6. The CC and bias are also given in the Fig. 6. Among these four seasons, all these satellite products get the lowest $\mathrm{CC}$ and the largest bias in winter [December-February (DJF)]. This indicates that all these products cannot perform well in the wintertime. This may be because the PMW scattering algorithms in these products cannot discriminate the scatterings from snow and ice on the cold surface and those from ice crystals in the atmosphere, which turn to precipitation (Ebert et al. 2007; Dinku et al. 2010). Another possible reason is that when microwave data are absent, precipitation retrieval of T-rt and T-adj mainly relies on IR data. IR-based precipitation estimates do not perform well in mountainous regions (Hong et al. 2007; Bitew and Gebremichael 2011). The results of comparison among T-rt, T-adj, C-rt, and C-adj in Fig. 6 are consistent with results in Figs. 4 and 5. In the Lhasa basin, T-rt largely overestimates precipitation in these four seasons, while C-rt underestimates $26.69 \%$ precipitation in the summer [June-August (JJA)], in which precipitation is highest among four seasons. T-adj and C-adj have good correlations with IGSNRR in all seasons except the winter.

\section{b. Performances of streamflow simulation}

The simulation skills of daily streamflow forced by IGSNRR, T-rt, T-adj, C-rt, C-adj, and C-ga in the Lhasa and Gongbo basins with benchmarked model parameter values from using IGSNRR are summarized in Table 2. Figure 7 presents the streamflow hydrographs for these simulations in these two basins. The simulation forced by IGSNRR could capture the peak flows and achieve good performances in the Lhasa and Gongbo basins, with all NSE values above 0.7 . The spatial pattern of the multiple year average for the simulated snowmelt, evapotranspiration (ET), and water yield in the Lhasa basin (2000-08) and the Gongbo basin (2000-10) are shown in Fig. 8.

For the TMPA series, T-rt results in negative NSE and large VE. This shows T-rt cannot be directly used for streamflow simulation in this region. But previous studies (Michailovsky et al. 2013; Finsen et al. 2014) revealed T-rt version 6 could be utilized for the streamflow simulations in Yarlung Zangbo River. This may be because of the degradation of T-rt from version 6 to version 7 in the Tibetan Plateau (Chen et al. 2013). As adjusted by the gauge dataset, the VE of simulation forced by T-adj has been largely reduced, compared to the simulation forced by T-rt. T-adj obtained a moderate simulation performance in the Lhasa basin and calibration period of Gongbo basin, with NSE ranging from 0.32 to 0.55 .

For the CMORPH series, first it should be noticed that the bad performances of C-rt, C-adj, and C-ga during the calibration period from 2000 to 2005 in the Gongbo basin are not consistent with their performances during the validation period from 2006 to 2010, as shown in the hydrographs in Fig. 7. Their large underestimation in the simulated discharges during the calibration period in the Gongbo basin is mainly due to the relatively high proportion of missing grids, as shown in Fig. 3. Their bad performances during the calibration period do not reflect the intrinsic properties of the retrieval algorithms. The streamflow simulation forced by $\mathrm{C}$-rt in the Lhasa and Gongbo basins shows an underestimation, which is consistent with the results of the statistical validation. Compared to C-rt, $\mathrm{C}$-adj achieved an improved performance for the streamflow simulation with higher NSE and lower VE. C-ga obtains the good performance that is comparable to IGSNRR in the Lhasa basin, while in the Gongbo basin the performance is close to $\mathrm{C}$-adj.

Detailed intercomparison among the performances of simulated discharges forced by IGSNRR, T-adj, C-adj, and C-ga can be also inferred from the Taylor diagram of Fig. 9. The Taylor diagram is an integrated evaluation of the simulation and shows that IGSNRR achieves the best performance among these four datasets. In the Lhasa basin, C-ga obtains a better performance than $\mathrm{C}$-adj, and C-adj is better than T-adj. In the Gongbo basin, the simulation performance forced by $\mathrm{C}$-ga is almost the same as C-adj, and C-adj is also better than T-adj. 
(a) Lhasa

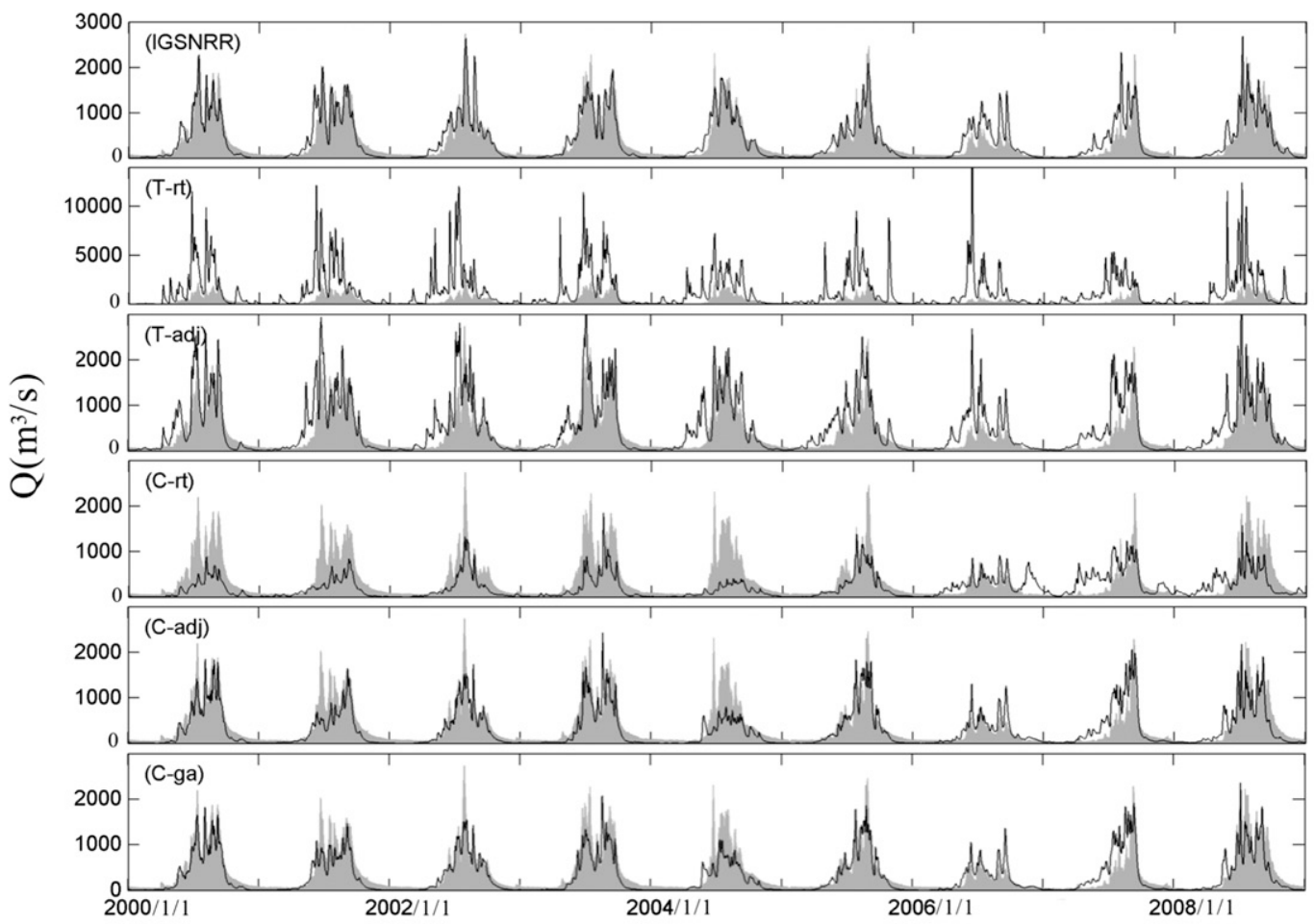

(b) Gongbo

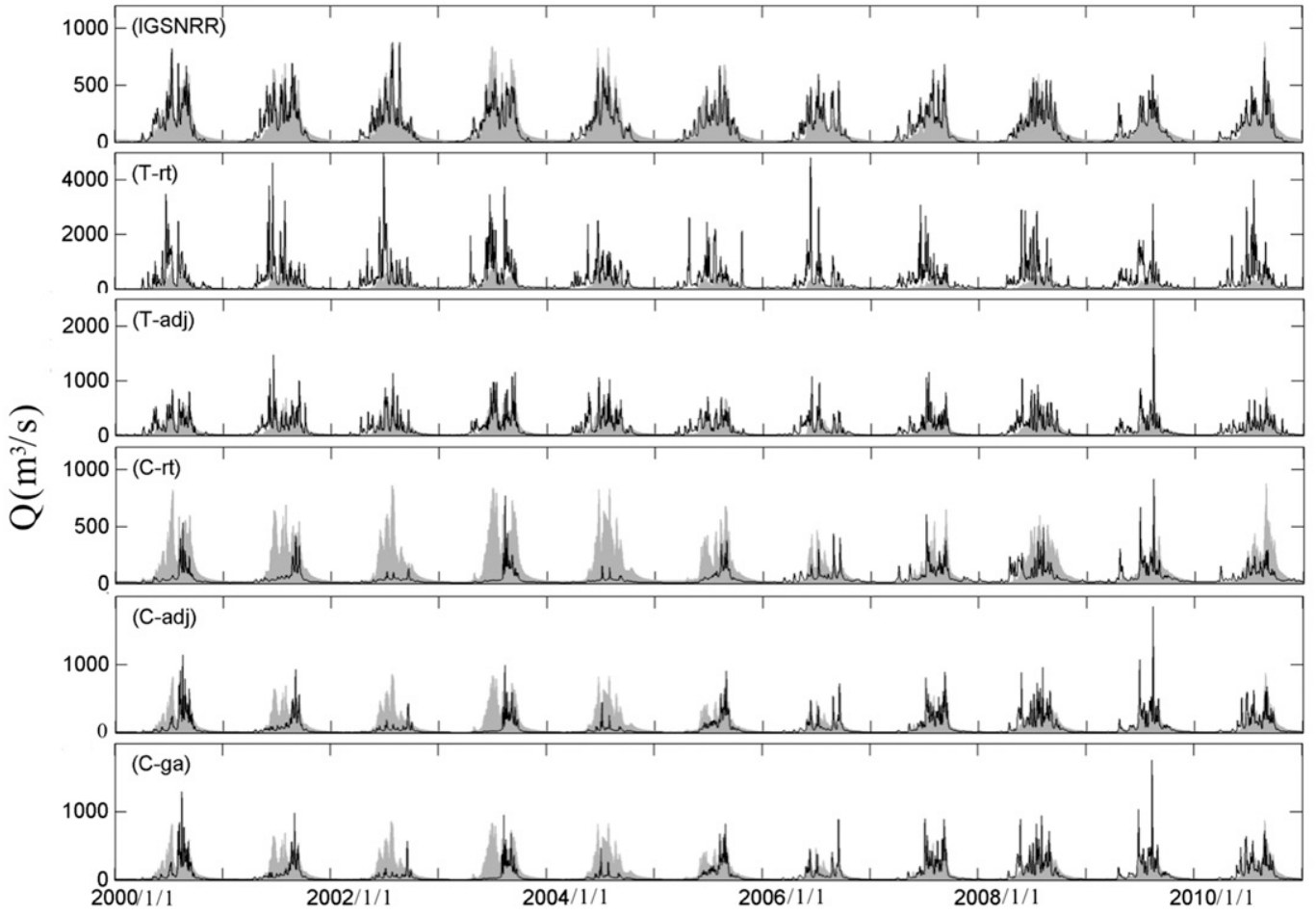

FIG. 7. The daily streamflow simulated by the VIP model with [from top to bottom in (a),(b)] IGSNRR, T-rt, T-adj, C-rt, C-adj, and C-ga as precipitation forcing in the (a) Lhasa (2000-08) and (b) Gongbo (2000-10) basins. The shaded background is the observed discharge and the black line is the simulated discharge. 
(a) snowmelt
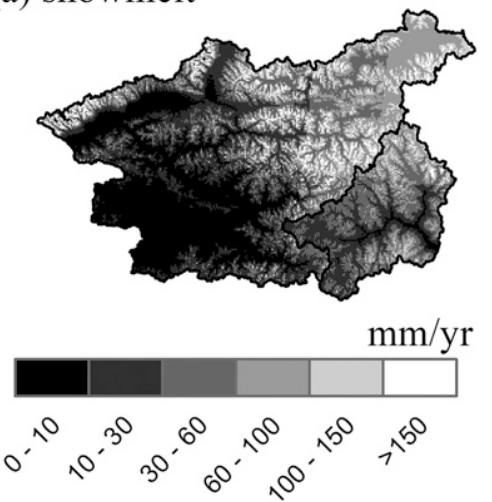

(b) ET

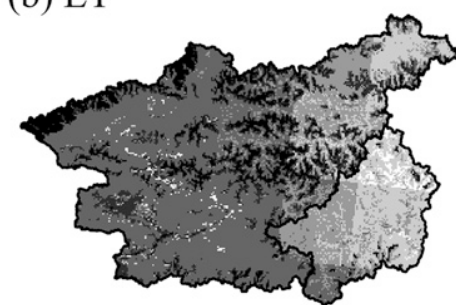

$\mathrm{mm} / \mathrm{yr}$ (c) water yield

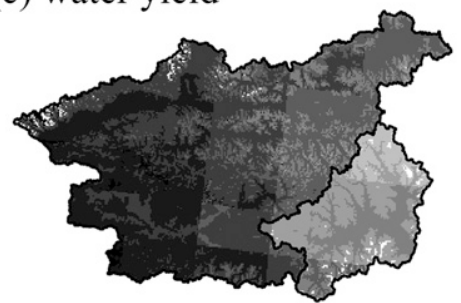

$\mathrm{mm} / \mathrm{yr}$

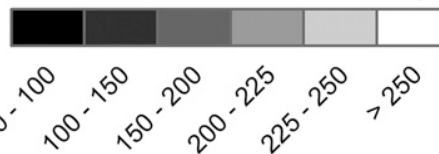

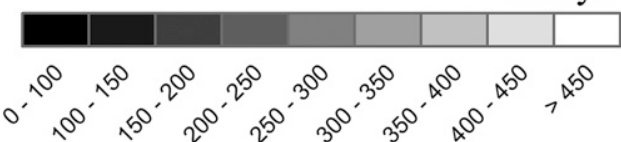

FIG. 8. The multiyear average of (a) snowmelt, (b) evapotranspiration, and (c) water yield simulated by the VIP model with IGSNRR precipitation forcing in the Lhasa basin from 2000 to 2008 and the Gongbo basin from 2000 to 2010.

Overall, intercomparison among the performances of the streamflow simulations with the benchmarked model parameter values by IGSNRR demonstrates that C-adj gets good simulation performances and its precipitation is very close to IGSNRR, whereas moderate simulation skills are achieved by $\mathrm{T}$-adj with the same parameter values.

\section{Discussion}

Because different precipitation forcing datasets have different characteristics, it is unfair to use one set of parameter values, which were calibrated by the gaugebased dataset, to compare its streamflow simulating efficiency. Bitew et al. (2012) and Xue et al. (2013) found the efficiency of hydrological simulation turns to be higher when using the parameters calibrated from specific rainfall satellite data than using the parameters calibrated by the gauged data. An experiment of T-adj recalibration was conducted in the Lhasa basin. The optimized parameter values and the simulation skills are shown in Table 3. Compared to the simulation performance of T-adj without recalibration, as shown in Table 2 , the major changes are the increase of $\lambda 1$ (the temperature lapse rate above the critical elevation) and the decrease of $B$ (shape parameter of the variable infiltration curve). The increase of $\lambda 1$ leads to reduced snow and ice melt in the high mountains. The decrease of $B$ results in more water infiltrating the soil and then increases the evapotranspiration. These changes of

\section{(a) Lhasa}
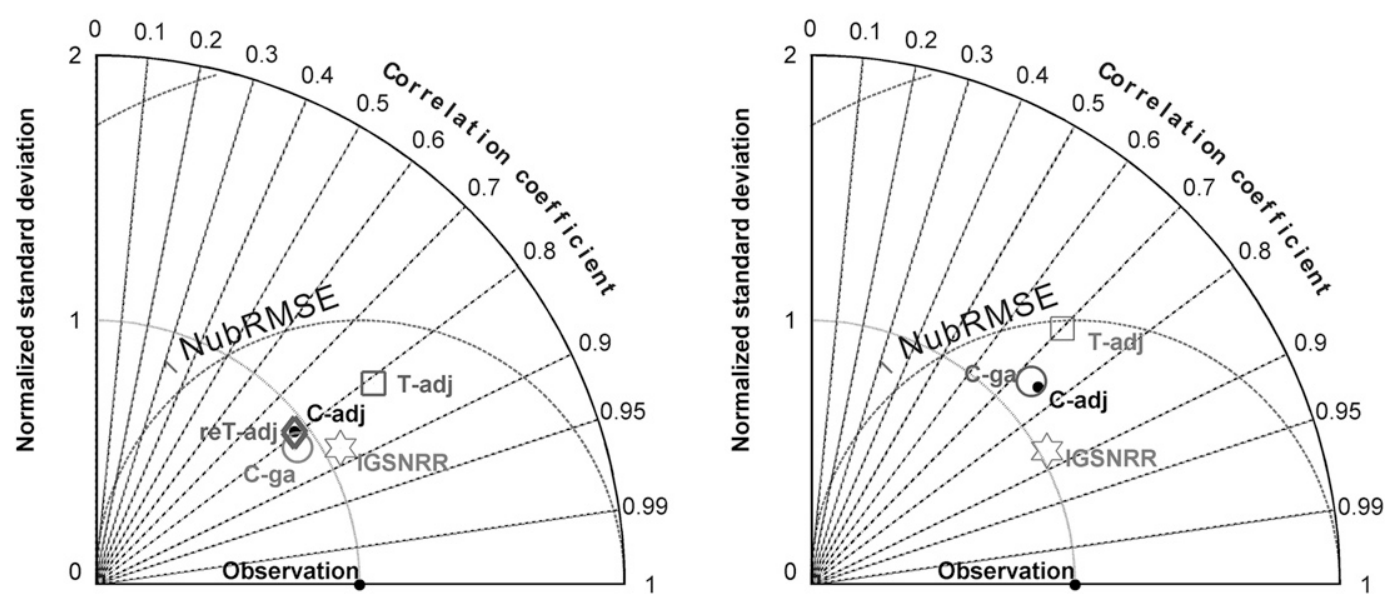

FIG. 9. Taylor diagram for statistics of the simulated discharges forced by IGSNRR (star), T-adj (square), C-adj (dot), C-ga (circle), and recalibration of T-adj (diamond) in the Lhasa basin. The performance during the validation period in the (a) Lhasa and (b) Gongbo basins. 
TABLE 3. The parameter values and simulation performance of recalibration $\mathrm{T}$-adj in the Lhasa basin.

\begin{tabular}{|c|c|c|c|c|c|c|c|c|}
\hline \multirow[b]{2}{*}{$\lambda 1$} & \multirow[b]{2}{*}{$B$} & \multirow[b]{2}{*}{$N$} & \multirow[b]{2}{*}{ Tguz } & \multirow[b]{2}{*}{ Tglz } & \multicolumn{2}{|c|}{ Calibration } & \multicolumn{2}{|c|}{ Validation } \\
\hline & & & & & NSE & VE (\%) & NSE & VE (\%) \\
\hline 0.71 & 0.3 & 0.5 & 0.07 & 0.008 & 0.65 & -1.39 & 0.6 & 11.98 \\
\hline
\end{tabular}

processes in the hydrological modeling are due to the higher precipitation estimates of $\mathrm{T}$-adj than those of IGSNRR (Fig. 10). The performance of streamflow simulation with T-adj recalibration is shown in Table 3 , which is also compared with the performance without recalibration in the Taylor diagram (Fig. 9a). It can be seen that the performance of $\mathrm{T}$-adj with parameter recalibration has significantly improved compared to that without parameter recalibration. But this also induces different estimation of water balance components, such as the increase of ET and reduction of the glacier melt, as shown in Fig. 10. This is a common problem for the hydrological simulation in the alpine region. An underestimation or overestimation of precipitation may lead to compensation for increased or decreased glacier melt in the model calibration (Schaefli et al. 2005). Thus, caution should be exercised in selecting precipitation data for the estimation of glacier melt in alpine regions.

\section{Conclusions}

This paper comprehensively evaluated five state-ofthe-art satellite-based precipitation products, including two near-real-time products (T-rt and C-rt), their corresponding gauge-adjusted versions (T-adj and $\mathrm{C}$-adj), and the gauge-satellite blended precipitation product (C-ga) in the Lhasa and Gongbo basins, which are located in the monsoon-dominated alpine region in the southeast Tibetan Plateau, by statistical validation and hydrological simulation approaches. The statistical validation was conducted at grid and basin scales by comparing against a gauge-based synthetic precipitation dataset. The results show that T-rt largely overestimates the volume of precipitation, while C-rt underestimates the precipitation, especially in the summer season. These two products have different POD and FAR scores, but generally they achieve comparable precipitation detection performances with similar CSI scores. T-rt errors mainly come from overestimation of the volume of observed rainfall correctly detected, while C-rt errors are from underestimation of the volume of observed rainfall correctly detected and overestimation of the volume of falsely alarmed rainfall. Two adjusted products ( $\mathrm{T}$-adj and $\mathrm{C}$-adj) show more improved performance than the real-time versions (T-rt and C-rt). All

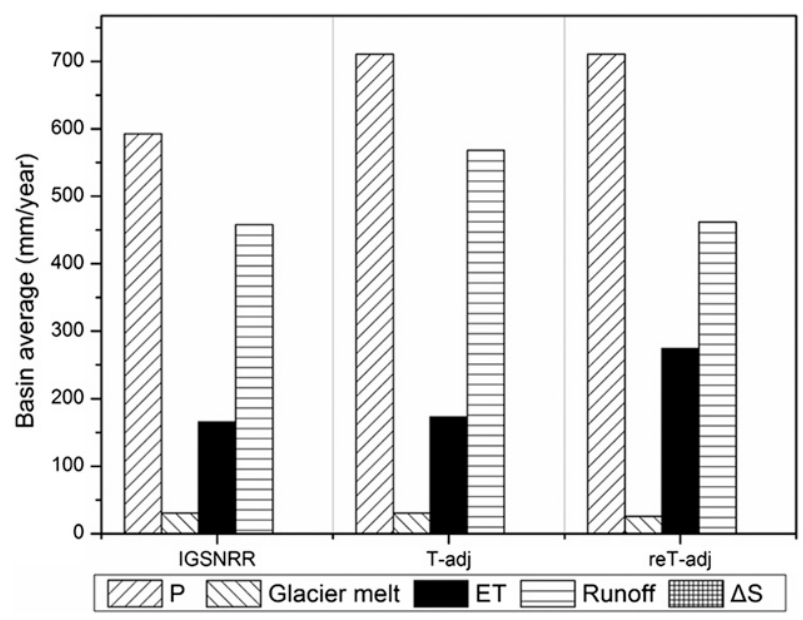

FIG. 10. The multiyear average of water balance components(columns from left to right) precipitation, glacier melt, evapotranspiration, runoff, and $\Delta S$-for the hydrological simulation driven by (from left to right) IGSNRR, T-adj with benchmarked parameter values by IGSNRR, and T-adj with parameter recalibration (reTadj) in the Lhasa basin during the period from 2000 to 2008. (The change of soil water and groundwater storage $\Delta S$ is very small.)

these satellite-based precipitation products perform better in summer than winter.

A process-based distributed VIP model was employed for streamflow simulation in the Lhasa and Gongbo basins. The streamflow forced by T-rt largely overestimates the discharge, while the simulation driven by C-rt shows underestimation. $\mathrm{T}$-adj and $\mathrm{C}$-adj have great potential for hydrological simulation. C-adj achieved a good performance for streamflow with benchmarked model parameter values through the gauge-based dataset, while T-adj needs recalibration to achieve the good simulation skills. In the Lhasa basin (precipitation-gauged region), C-ga has a similar performance as the gauge-based dataset, and in the Gongbo basin (precipitation ungauged), it behaves similarly to C-adj. This study may serve as a reference for precipitation dataset selection for hydrological applications in the southeast Tibetan Plateau.

Acknowledgments. This work was funded by the National Basic Research Program of China (Grant 2012CB957802), the project of Chinese National Natural Science Foundation (31171451), and "135" Key Project for the Strategic Science Plan in IGSNRR, CAS. We acknowledge the suggestions from two anonymous reviewers.

\section{REFERENCES}

AghaKouchak, A., and A. Mehran, 2013: Extended contingency table: Performance metrics for satellite observations and climate model simulations. Water Resour. Res., 49, 7144-7149, doi:10.1002/wrcr.20498. 
Bitew, M. M., and M. Gebremichael, 2011: Assessment of satellite rainfall products for streamflow simulation in medium watersheds of the Ethiopian highlands. Hydrol. Earth Syst. Sci., 15, 1147-1155, doi:10.5194/hess-15-1147-2011.

,-- L. T. Gebremichael, and Y. A. Bayissa, 2012: Evaluation of high-resolution satellite rainfall products through streamflow simulation in a hydrological model of a small mountain watershed in Ethiopia. J. Hydrometeor., 13, 338350, doi:10.1175/2011JHM1292.1.

Bookhagen, B., and D. W. Burbank, 2010: Toward a complete Himalayan hydrological budget: Spatiotemporal distribution of snowmelt and rainfall and their impact on river discharge. J. Geophys. Res., 115, F03019, doi:10.1029/2009JF001426.

Chen, S., and Coauthors, 2013: Similarity and difference of the two successive V6 and V7 TRMM Multisatellite Precipitation Analysis performance over China. J. Geophys. Res. Atmos., 118, 13 060-13 074, doi:10.1002/2013JD019964.

Dinku, T., S. J. Connor, and P. Ceccato, 2010: Comparison of CMORPH and TRMM-3B42 over mountainous regions of Africa and South America. Satellite Rainfall Applications for Surface Hydrology, M. Gebremichael and F. Hossain, Eds., Springer, 193-204.

Duan, Q., S. Sorooshian, and V. Gupta, 1992: Effective and efficient global optimization for conceptual rainfall-runoff models. Water Resour. Res., 28, 1015-1031, doi:10.1029/ 91WR02985.

—, V. K. Gupta, and S. Sorooshian, 1993: Shuffled complex evolution approach for effective and efficient global minimization. J. Optim. Theory Appl., 76, 501-521, doi:10.1007/ BF00939380.

Ebert, E. E., J. E. Janowiak, and C. Kidd, 2007: Comparison of near-real-time precipitation estimates from satellite observations and numerical models. Bull. Amer. Meteor. Soc., 88, 47-64, doi:10.1175/BAMS-88-1-47.

FAO, IIASA, ISRIC, ISSCAS, and JRC, 2012: Harmonized World Soil Database (version 1.2). FAO and IIASA, accessed 15 March 2014. [Available online at http://webarchive.iiasa.ac.at/Research/ LUC/External-World-soil-database/HTML/index.html?sb=1.]

Ferraro, R. R., 1997: Special sensor microwave imager derived global rainfall estimates for climatological applications. J. Geophys. Res., 102, 16715-16735, doi:10.1029/97JD01210.

— cipitation characteristics over land from the NOAA-15 AMSU sensor. Geophys. Res. Lett., 27, 2669-2672, doi:10.1029/ 2000 GL011665.

Finsen, F., C. Milzow, R. Smith, P. Berry, and P. Bauer-Gottwein, 2014: Using radar altimetry to update a large-scale hydrological model of the Brahmaputra River basin. Hydrol. Res., 45, 148-164, doi:10.2166/nh.2013.191.

Gao, Y. C., and M. F. Liu, 2013: Evaluation of high-resolution satellite precipitation products using rain gauge observations over the Tibetan Plateau. Hydrol. Earth Syst. Sci. 17, 837-849, doi:10.5194/hess-17-837-2013.

Guo, W., and Coauthors, 2014: The second glacier inventory dataset of China (version 1.0). Cold and Arid Regions Science Data Center, accessed 12 January 2015, doi:10.3972/glacier.001.2013.db.

Hong, Y., D. Gochis, J. T. Cheng, K. L. Hsu, and S. Sorooshian, 2007: Evaluation of PERSIANN-CCS rainfall measurement using the NAME event rain gauge network. J. Hydrometeor., 8, 469-482, doi:10.1175/JHM574.1.

Hrachowitz, M., and Coauthors, 2013: A decade of Predictions in Ungauged Basins (PUB)-A review. Hydrol. Sci. J., 58, 11981255, doi:10.1080/02626667.2013.803183.
Huang, F., and X. Mo, 2015: Water budget and its variation in Hutuo River basin predicted with the VIP ecohydrological model. Proc. Int. Assoc. Hydrol. Sci., 368, 460-465, doi:10.5194/ piahs-368-460-2015.

Huffman, G. J., R. F. Adler, D. T. Bolvin, G. Gu, E. J. Nelkin, K. P. Bowman, Y. Hong, and E. F. Stocker, 2007: The TRMM Multisatellite Precipitation Analysis (TMPA): Quasi-global, multiyear, combined-sensor precipitation estimates at fine scales. J. Hydrometeor., 8, 38-55, doi:10.1175/JHM560.1.

,,-- , and E. J. Nelkin, 2010: The TRMM MultiSatellite Precipitation Analysis (TMPA). Satellite Rainfall Applications for Surface Hydrology, M. Gebremichael and F. Hossain, Eds., Springer, 3-22, doi:10.1007/978-90-481-2915-7_1.

Immerzeel, W. W., L. P. H. van Beek, and M. F. P. Bierkens, 2010: Climate change will affect the Asian water towers. Science, 328, 1382-1385, doi:10.1126/science.1183188.

—, L. Petersen, S. Ragettli, and F. Pellicciotti, 2014: The importance of observed gradients of air temperature and precipitation for modeling runoff from a glacierized watershed in the Nepalese Himalayas. Water Resour. Res., 50, 2212-2226, doi:10.1002/2013WR014506.

Joyce, R. J., J. E. Janowiak, P. A. Arkin, and P. Xie, 2004: CMORPH: A method that produces global precipitation estimates from passive microwave and infrared data at high spatial and temporal resolution. J. Hydrometeor., 5, 487-503, doi:10.1175/1525-7541(2004)005<0487:CAMTPG>2.0.CO;2.

_ P. Xie, and J. E. Janowiak, 2010: CMORPH: A "morphing" approach for high resolution precipitation product generation. Satellite Rainfall Applications for Surface Hydrology, M. Gebremichael and F. Hossain, Eds., Springer, 23-37, doi:10.1007/978-90-481-2915-7_2.

Kidd, C., and V. Levizzani, 2011: Status of satellite precipitation retrievals. Hydrol. Earth Syst. Sci., 15, 1109-1116, doi:10.5194/ hess-15-1109-2011.

Kummerow, C., and Coauthors, 2001: The evolution of the Goddard profiling algorithm (GPROF) for rainfall estimation from passive microwave sensors. J. Appl. Meteor. Climatol., 40, 1801-1820, doi:10.1175/1520-0450(2001)040<1801:TEOTGP>2.0.CO;2.

Li, F., Y. Zhang, Z. Xu, C. Liu, Y. Zhou, and W. Liu, 2014: Runoff predictions in ungauged catchments in southeast Tibetan Plateau. J. Hydrol., 511, 28-38, doi:10.1016/ j.jhydrol.2014.01.014.

Lin, R., C. Li, Y. Zhang, and Y. Xing, 2001: Agro-Climate Resources in Lhasa, Tibet. China Meteorological Press, 142 pp.

Liu, S., X. Mo, W. Zhao, V. Naeimi, D. Dai, C. Shu, and L. Mao, 2009: Temporal variation of soil moisture over the Wuding River basin assessed with an eco-hydrological model, in-situ observations and remote sensing. Hydrol. Earth Syst. Sci., 13, 1375-1398, doi:10.5194/hess-13-1375-2009.

Lu, C., L. Wang, G. Xie, and Y. Leng, 2007: Altitude effect of precipitation and spatial distribution of Qinghai-Tibetan Plateau. J. Mt. Sci., 25, 655-663.

Lutz, A. F., W. W. Immerzeel, A. B. Shrestha, and M. F. P. Bierkens, 2014: Consistent increase in High Asia's runoff due to increasing glacier melt and precipitation. Nat. Climate Change, 4, 587-592, doi:10.1038/nclimate2237.

Maurer, E. P., A. W. Wood, J. C. Adam, D. P. Lettenmaier, and B. Nijssen, 2002: A long-term hydrologically based dataset of land surface fluxes and states for the conterminous United States. J. Climate, 15, 3237-3251, doi:10.1175/1520-0442(2002)015<3237: ALTHBD $>2.0 . \mathrm{CO} ; 2$.

Meng, J., L. Li, Z. Hao, J. Wang, and Q. Shao, 2014: Suitability of TRMM satellite rainfall in driving a distributed hydrological 
model in the source region of Yellow River. J. Hydrol., 509, 320-332, doi:10.1016/j.jhydrol.2013.11.049.

Michailovsky, C. I., C. Milzow, and P. Bauer-Gottwein, 2013: Assimilation of radar altimetry to a routing model of the Brahmaputra River. Water Resour. Res., 49, 4807-4816, doi:10.1002/wrcr.20345.

Mo, X., and S. Liu, 2001: Simulating evapotranspiration and photosynthesis of winter wheat over the growing season. Agric. For. Meteor., 109, 203-222, doi:10.1016/S0168-1923(01)00266-0.

,,-- Z. Lin, and W. Zhao, 2004: Simulating temporal and spatial variation of evapotranspiration over the Lushi basin. J. Hydrol., 285, 125-142, doi:10.1016/j.jhydrol.2003.08.013.

,,,--- S. Wang, and S. Hu, 2014: Trends in land surface evapotranspiration across China with remotely sensed NDVI and climatological data in 1981-2010. Hydrol. Sci. J., doi:10.1080/ 02626667.2014.950579, in press.

Nikolopoulos, E. I., E. N. Anagnostou, F. Hossain, M. Gebremichael, and M. Borga, 2010: Understanding the scale relationships of uncertainty propagation of satellite rainfall through a distributed hydrologic model. J. Hydrometeor., 11, 520-532, doi:10.1175/ 2009JHM1169.1.

Ohta, T., H. Yabuki, T. Koike, T. Ohata, M. Koike, and Y. Zhang, 1994: Hydrological observations in the Tanggula Mountains, the Tibetan Plateau-Discharge, soil moisture and ground temperature. Bull. Glaciol. Res., 12, 49-56.

Palazzi, E., J. von Hardenberg, and A. Provenzale, 2013: Precipitation in the Hindu-Kush Karakoram Himalaya: Observations and future scenarios. J. Geophys. Res. Atmos., 118, 85-100, doi:10.1029/2012JD018697.

Peng, B., J. Shi, W. Ni-Meister, T. Zhao, and D. Ji, 2014: Evaluation of TRMM Multisatellite Precipitation Analysis (TMPA) products and their potential hydrological application at an arid and semiarid basin in China. IEEE J. Sel. Top. Appl. Earth Obs. Remote Sens., 7, 3915-3930, doi:10.1109/ JSTARS.2014.2320756.

Qiu, J., and Coauthors, 2013: Intercomparison of microwave remote-sensing soil moisture data sets based on distributed eco-hydrological model simulation and in situ measurements over the north China plain. Int. J. Remote Sens., 34, 6587-6610, doi:10.1080/01431161.2013.788799.

Schaefli, B., B. Hingray, M. Niggli, and A. Musy, 2005: A conceptual glacio-hydrological model for high mountainous catchments. Hydrol. Earth Syst. Sci., 9, 95-109, doi:10.5194/ hess-9-95-2005.

Shepard, D. S., 1984: Computer mapping: The SYMAP interpolation algorithm. Spatial Statistics and Models, G. L. Gaile and C. J. Willmott, Eds., D. Reidel, 133-145.

Sorooshian, S., K. L. Hsu, X. Gao, H. V. Gupta, B. Imam, and D. Braithwaite, 2000: Evaluation of PERSIANN system satellite-based estimates of tropical rainfall. Bull. Amer. Meteor. Soc., 81, 2035-2046, doi:10.1175/1520-0477(2000)081<2035: EOPSSE $>2.3 . \mathrm{CO} ; 2$.

Stisen, S., and I. Sandholt, 2010: Evaluation of remote-sensing based rainfall products through predictive capability in hydrological runoff modeling. Hydrol. Processes, 24, 879-891, doi:10.1002/hyp.7529.

Symeonakis, E., R. Bonifaçio, and N. Drake, 2009: A comparison of rainfall estimation techniques for sub-Saharan Africa. Int. J. Appl. Earth Obs. Geoinf., 11, 15-26, doi:10.1016/ j.jag.2008.04.002.

Tang, Q., A. W. Wood, and D. P. Lettenmaier, 2009: Real-time precipitation estimation based on index station percentiles. J. Hydrometeor., 10, 266-277, doi:10.1175/2008JHM1017.1.
Taylor, K. E., 2001: Summarizing multiple aspects of model performance in a single diagram. J. Geophys. Res., 106, 71837192, doi:10.1029/2000JD900719.

Thiemig, V., R. Rojas, M. Zambrano-Bigiarini, and A. D. Roo, 2013: Hydrological evaluation of satellite-based rainfall estimates over the Volta and Baro-Akobo basin. J. Hydrol., 499, 324-338, doi:10.1016/j.jhydrol.2013.07.012.

Tong, K., F. Su, D. Yang, L. Zhang, and Z. Hao, 2014a: Tibetan Plateau precipitation as depicted by gauge observations, reanalyses and satellite retrievals. Int. J. Climatol., 34, 265-285, doi:10.1002/joc. 3682 .

,,,---- , and,$- 2014 \mathrm{~b}$ : Evaluation of satellite precipitation retrievals and their potential utilities in hydrologic modeling over the Tibetan Plateau. J. Hydrol., 519, 423437, doi:10.1016/j.jhydrol.2014.07.044.

Vergara, H., Y. Hong, J. J. Gourley, E. N. Anagnostou, V. Maggioni, D. Stampoulis, and P. E. Kirstetter, 2014: Effects of resolution of satellite-based rainfall estimates on hydrologic modeling skill at different scales. J. Hydrometeor., 15, 593613, doi:10.1175/JHM-D-12-0113.1.

Wilks, D., 2006: Statistical Methods in the Atmospheric Sciences. 2nd ed. Academic Press, 627 pp.

Xie, J., 2010: Analysis of the observation results of temperature and precipitation over an Alpine Mountain, the Lhasa River basin. Ph.D. dissertation, Graduate University of Chinese Academy of Sciences, $117 \mathrm{pp}$.

__ J. Liu, M. Du, S. Kang, and K. Wang, 2009: Analysis of the observation results of temperature and precipitation over an Alpine Mountain, the Lhasa River basin. Prog. Geogr., 28, 223-230, doi:10.11820/dlkxjz.2009.02.009.

Xie, P., and A. Y. Xiong, 2011: A conceptual model for constructing high-resolution gauge-satellite merged precipitation analyses. J. Geophys. Res., 116, D21106, doi:10.1029/ 2011JD016118.

—, M. Chen, S. Yang, A. Yatagai, T. Hayasaka, Y. Fukushima, and C. Liu, 2007: A gauge-based analysis of daily precipitation over East Asia. J. Hydrometeor., 8, 607-626, doi:10.1175/ JHM583.1.

— S. H. Yoo, R. J. Joyce, and Y. Yarosh, 2011: Bias-corrected CMORPH: A 13-year analysis of high-resolution global precipitation. Geophysical Research Abstracts, Vol. 13, Abstract EGU2011-1809. [Available online at http://meetingorganizer. copernicus.org/EGU2011/EGU2011-1809.pdf.]

_ R. Joyce, and S. Wu, 2013: A 15-year high-resolution gaugesatellite merged analysis of precipitation. 27th Conf. on Hydrology, Austin, TX, Amer. Meteor. Soc., 3B.4. [Available online at https://ams.confex.com/ams/93Annual/webprogram/ Paper220506.html.]

Xue, X., Y. Hong, A. S. Limaye, J. J. Gourley, G. J. Huffman, S. I. Khan, C. Dorji, and S. Chen, 2013: Statistical and hydrological evaluation of TRMM-based Multi-satellite Precipitation Analysis over the Wangchu basin of Bhutan: Are the latest satellite precipitation products $3 \mathrm{~B} 42 \mathrm{~V} 7$ ready for use in ungauged basins? J. Hydrol., 499, 91-99, doi:10.1016/j.jhydrol.2013.06.042.

Yatagai, A., K. Kamiguchi, O. Arakawa, A. Hamada, N. Yasutomi, and A. Kitoh, 2012: APHRODITE constructing a long-term daily gridded precipitation dataset for Asia based on a dense network of rain gauges. Bull. Amer. Meteor. Soc., 93, 14011415, doi:10.1175/BAMS-D-11-00122.1.

Yilmaz, K. K., T. S. Hogue, K. L. Hsu, S. Sorooshian, H. V. Gupta, and T. Wagener, 2005: Intercomparison of rain gauge, radar, and satellite-based precipitation estimates with emphasis on hydrologic forecasting. J. Hydrometeor., 6, 497-517, doi:10.1175/JHM431.1. 
Yin, Z., X. Zhang, X. Liu, M. Colella, and X. Chen, 2008: An assessment of the biases of satellite rainfall estimates over the Tibetan Plateau and correction methods based on topographic analysis. J. Hydrometeor., 9, 301-326, doi:10.1175/2007JHM903.1.

Yong, B., D. Liu, J. Gourley, Y. Tian, G. Huffman, L. Ren, and Y. Hong, 2015: Global view of real-time TRMM Multisatellite Precipitation Analysis: Implication to its successor Global Precipitation Measurement mission. Bull. Amer. Meteor. Soc., 96, 283-296, doi:10.1175/BAMS-D-14-00017.1.

Zhang, L., F. Su, D. Yang, Z. Hao, and K. Tong, 2013: Discharge regime and simulation for the upstream of major rivers over
Tibetan Plateau. J. Geophys. Res. Atmos., 118, 8500-8518, doi:10.1002/jgrd.50665.

Zhang, X., Q. Tang, M. Pan, and Y. Tang, 2014: A long-term land surface hydrologic fluxes and states dataset for China. J. Hydrometeor., 15, 2067-2084, doi:10.1175/JHM-D-13-0170.1.

Zhang, Y., S. Liu, and Y. Ding, 2006: Observed degree-day factors and their spatial variation on glaciers in western China. Ann. Glaciol., 43, 301-306, doi:10.3189/ 172756406781811952.

Zhao, R. J., 1992: The Xinanjiang model applied in China. J. Hydrol., 135, 371-381, doi:10.1016/0022-1694(92)90096-E. 